\title{
Photostable abscisic acid agonists with a geometrically rigid cyclized side chain
}

Jun Takeuchi ${ }^{1 *}$, Saya Mimura ${ }^{1}$, Toshiyuki Ohnishi ${ }^{1,2}$, Yasushi Todoroki ${ }^{1,2^{*}}$

${ }^{I}$ Faculty of Agriculture, Shizuoka University, 836 Ohya, Suruga-ku, Shizuoka 422-8529, Japan ${ }^{2}$ Research Institute of Green Science and Technology, Shizuoka University, 836 Ohya, Suruga-ku, Shizuoka 422-8529, Japan

\section{Supporting Information}

1) Supplementary Figures

2) Synthesis of compounds $\mathbf{5}-\mathbf{1 5}$

3) ${ }^{1} \mathrm{H}$ and ${ }^{13} \mathrm{C}$ NMR spectrums of synthesized compounds 

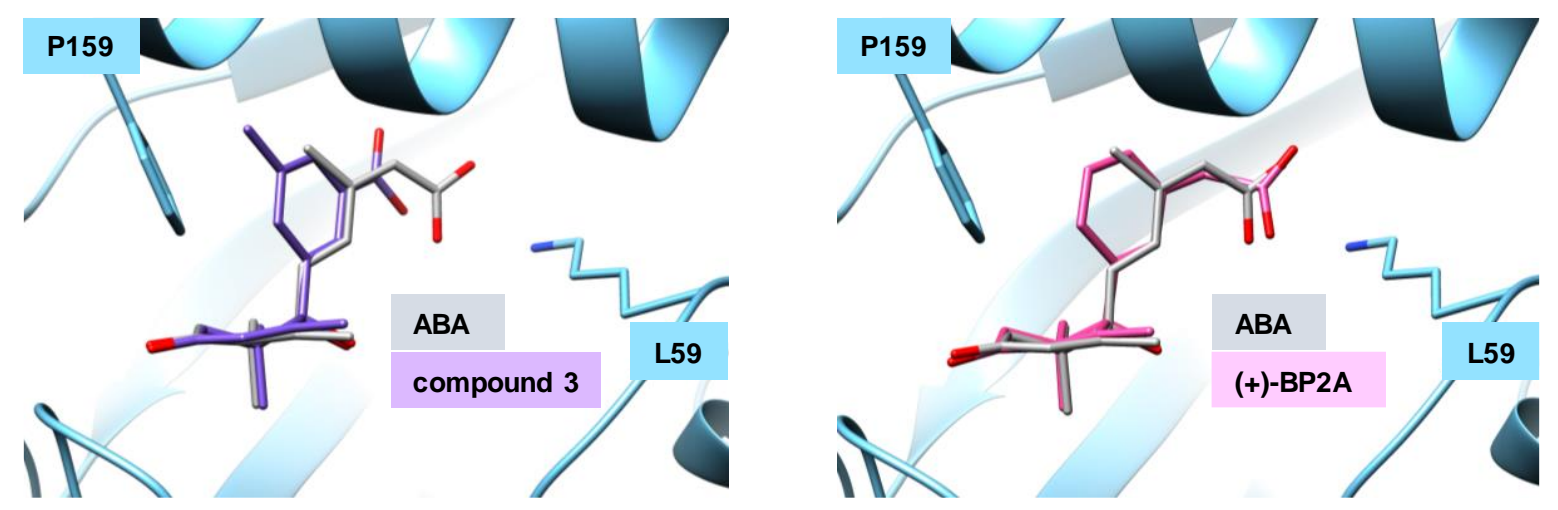

Figure S1 Superposition of compound 3 (left) or (+)-BP2A (right) with ABA in the PYR1-ABA complex (PDB ID: 3K90). ABA, gray sticks, compound 3 purple sticks, and (+)-BP2A pink sticks. 
(+)-isomer
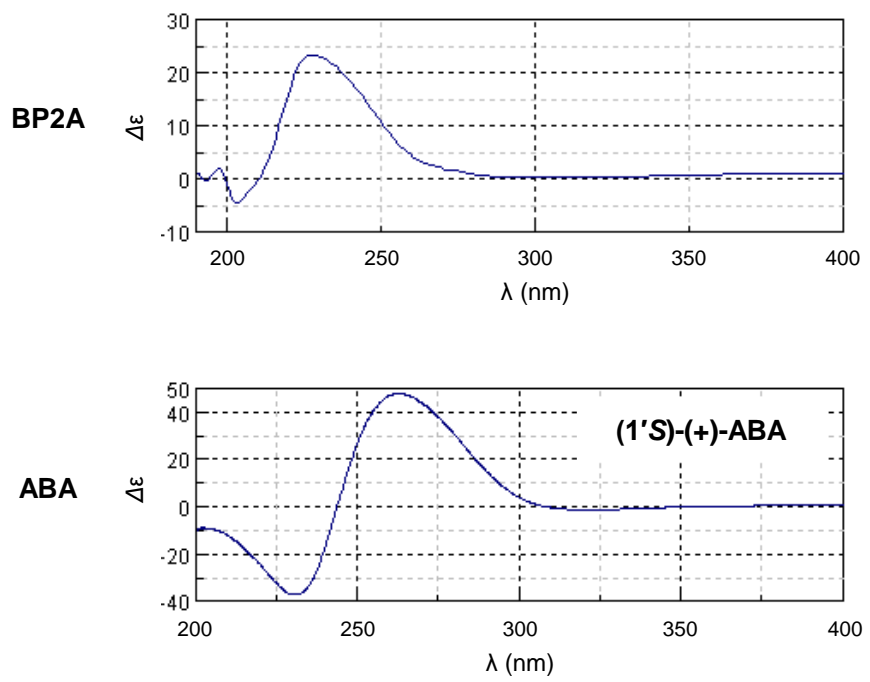

(-)-isomer

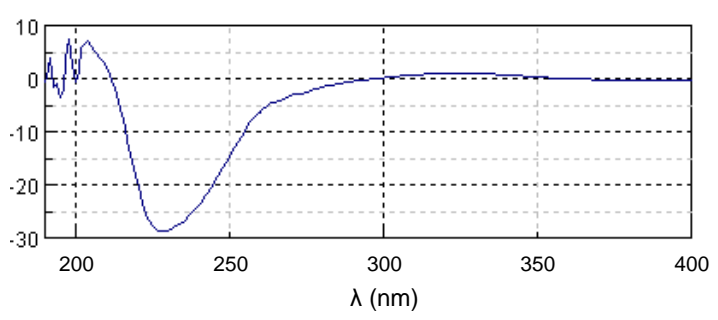

Figure S2 Experimental CD spectra of enantiomers of BP2A. 


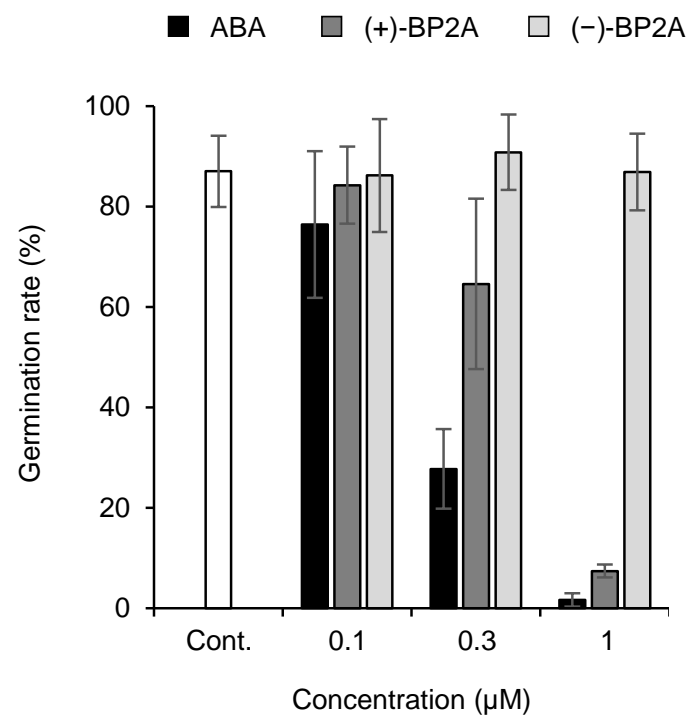

Figure S3 Comparison of the activity of (+)-BP2A and its (-)-isomer. Arabidopsis seed germination rate in response to (+)-BP2A and (-)-isomer at 60 h after stratification ( $n=3$, error bars represent SEs). 
$\rightarrow$ ABA $\quad \square-2 E-A B A-(+)-B P 2 A$

a

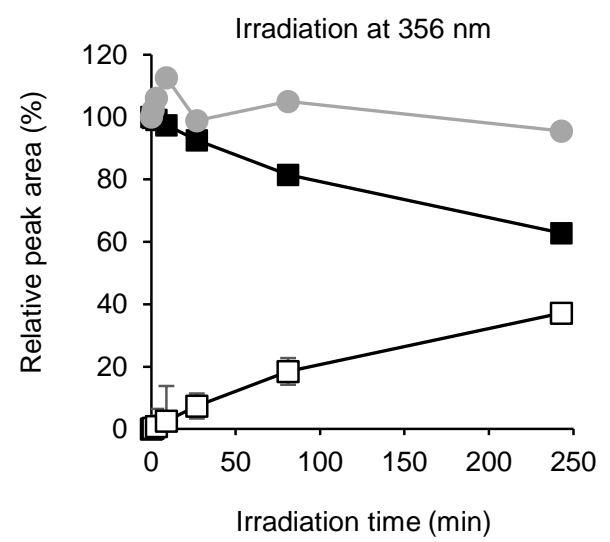

Irradiation at $254 \mathrm{~nm}$

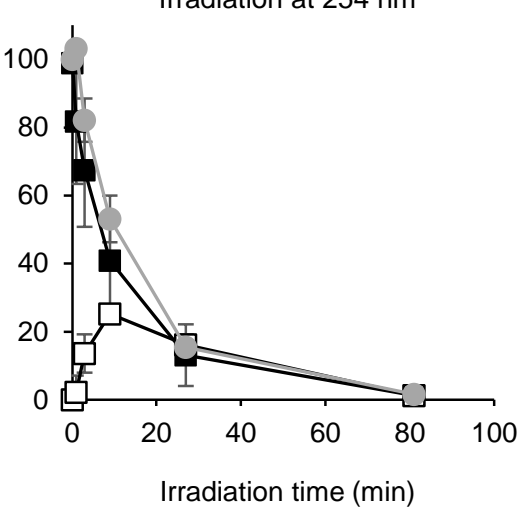

b

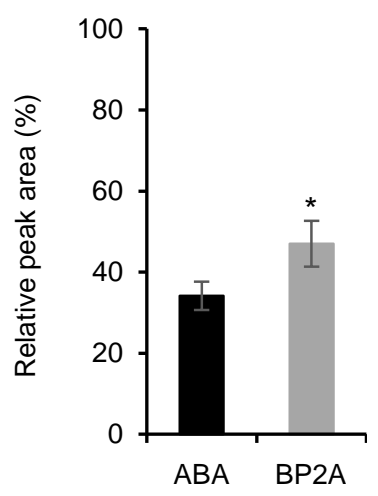

Figure S4 Photolysis of ABA and (+)-BP2A by UV irradiation or daylight. (a) Samples were irradiated with UV at $365 \mathrm{~nm}$ or $254 \mathrm{~nm}$ for indicated time. Data are mean $\pm S D(n=3)$. (b) Samples were exposed to direct sunlight for $6 \mathrm{~h}$ and then analyzed by HPLC. Values are averages from three independent experiments (error bars represent the standard deviations); ${ }^{*} P<0.05$ (Student's $t$ test). 
ABA
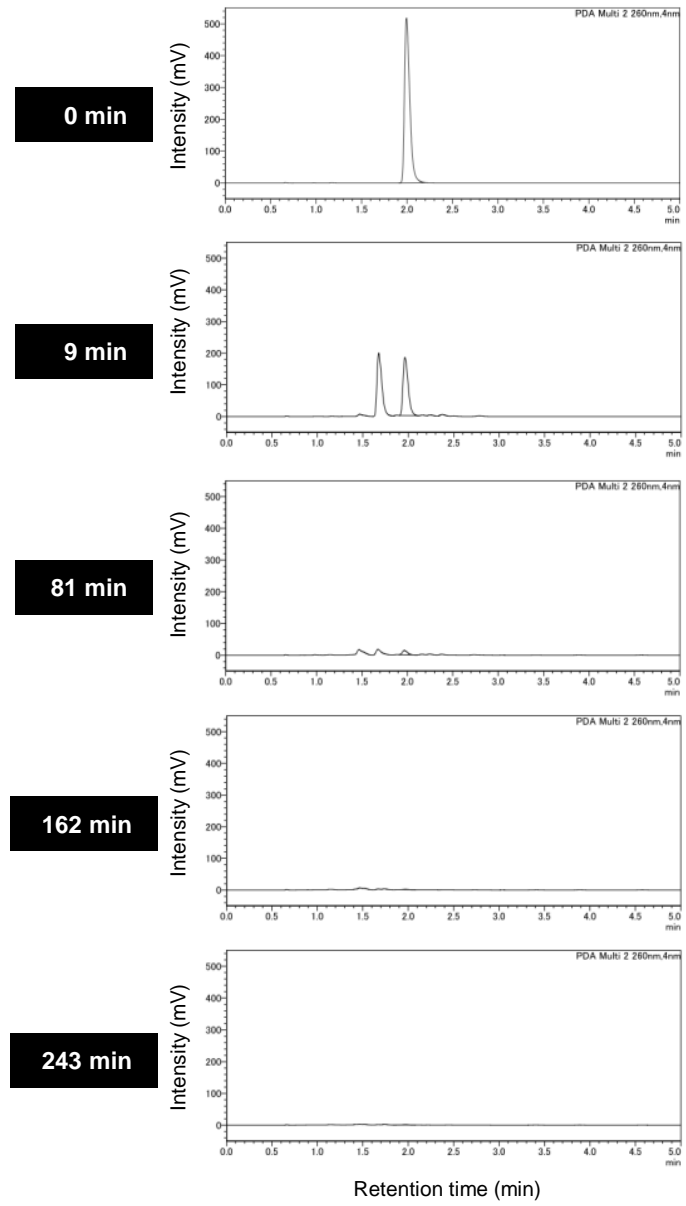

$(+)-B P 2 A$
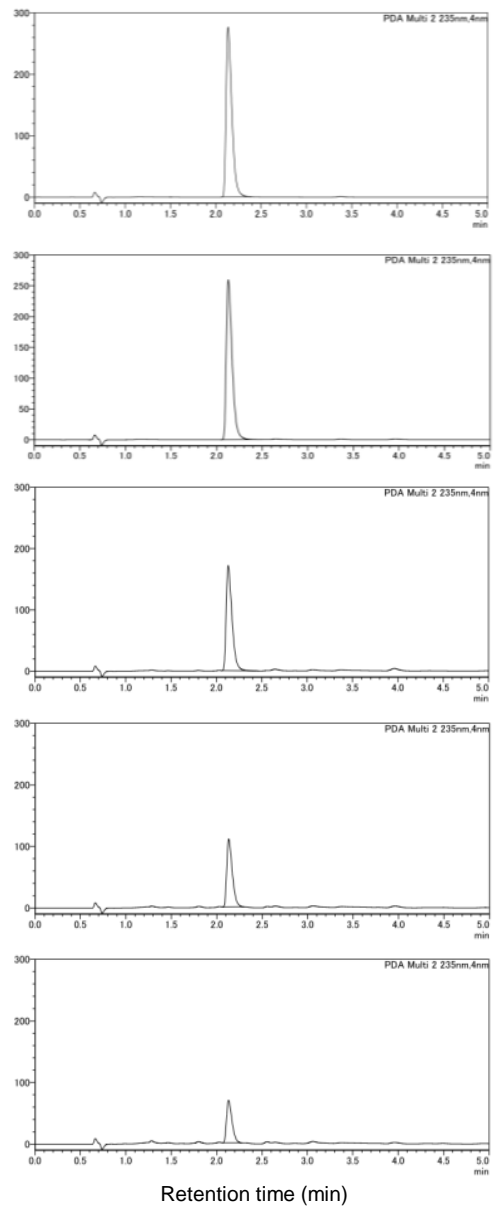

$( \pm)-7$
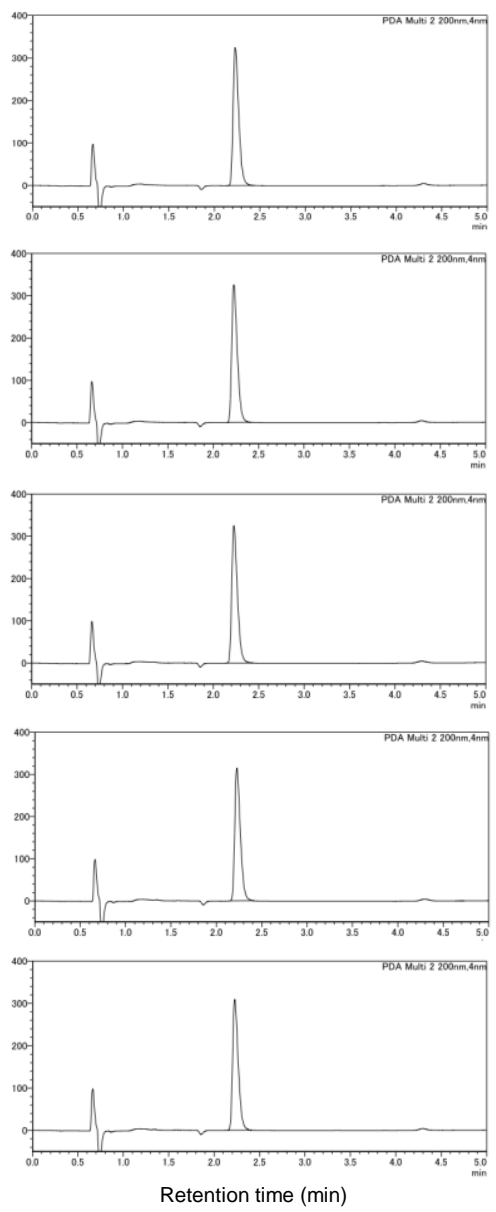

Figure S5 Representative HPLC data for the $302 \mathrm{~nm}$ UV irradiation tests related to Figure $2 \mathrm{~A}$. The HPLC conditions were as follows: column, Kinetex PS C18 $(100 \times 4.6 \mathrm{~mm}, 2.6, \mu \mathrm{m}$, Shimadzu GLC Ltd., Tokyo, Japan); solvent, $60 \% \mathrm{MeOH}$ in $\mathrm{H}_{2} \mathrm{O}$ containing $0.1 \% \mathrm{AcOH}$; flow rate, $1.5 \mathrm{~mL} \mathrm{~min}^{-1}$; and detection wavelength, 260 (ABA), 235 (BP2A) and 200 (compound 7) nm. The retention times of ABA, $(+)$-BP2A and $( \pm)-7$ are 2.0, 2.1 and 2.2 min, respectively. 


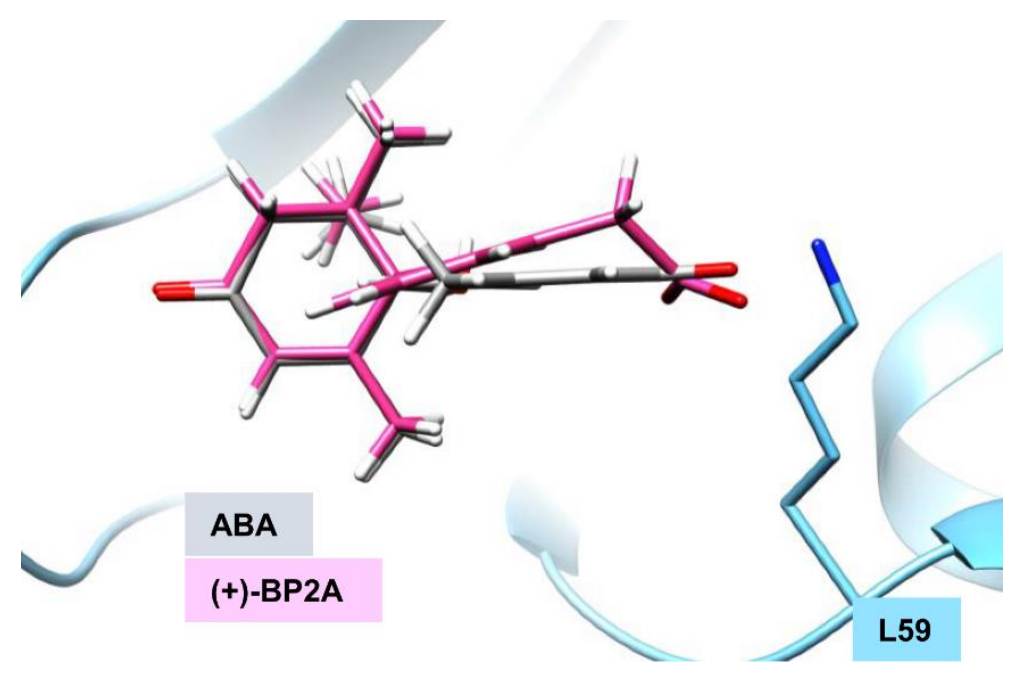

Figure S6 Structural comparison of ABA with (+)-BP2A in the ligand binding pocket of PYR1. Model of (+)-BP2A bound PYR1 constructed based on the crystal structure of the PYR1-ABA complex (PDB ID: $3 K 90)$. The geometry of (+)-BP2A was optimized at the B3LYP/6-31G(d) level of theory using Gaussian09 program. ABA, gray sticks and (+)-BP2A pink sticks. 
Incubated for $3 \mathrm{~h}$

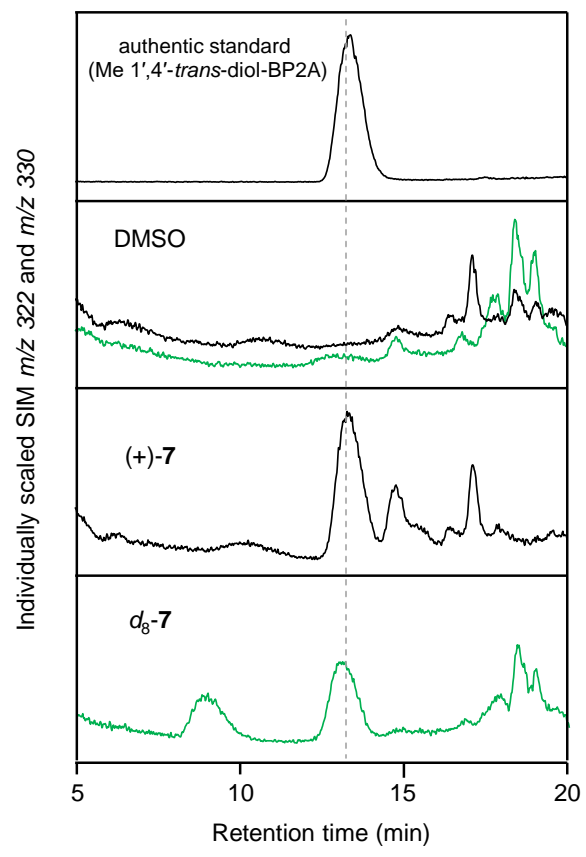

Incubated for $24 \mathrm{~h}$

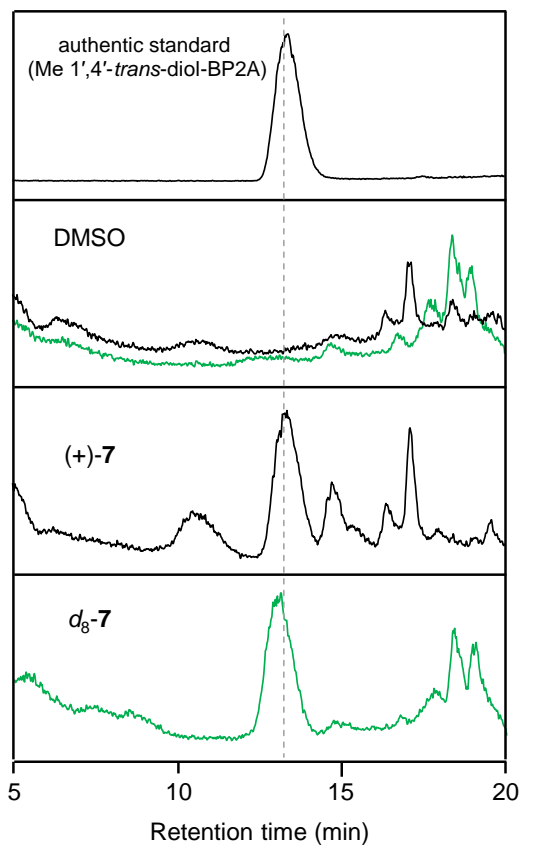

Retention time ( $\mathrm{min})$
Incubated for $48 \mathrm{~h}$

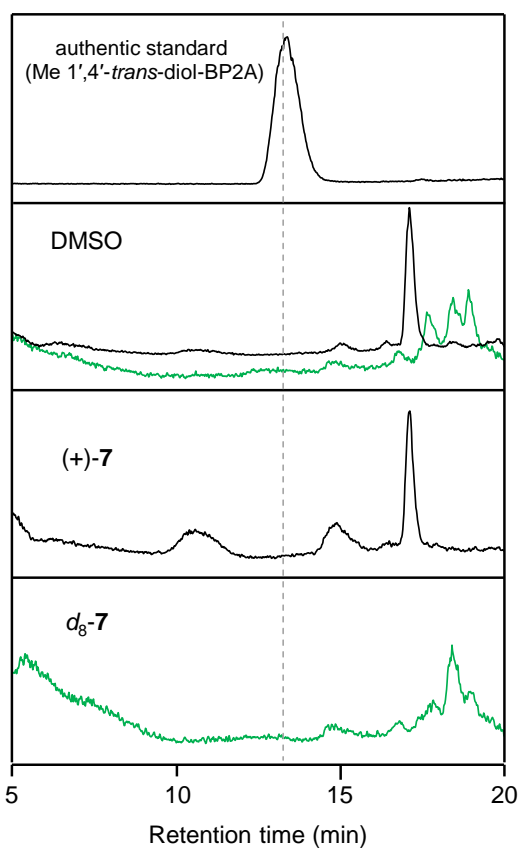

- $m / z 287[\mathrm{M}-\mathrm{H}]^{-} \quad-m / z 295[\mathrm{M}-\mathrm{H}]^{-}$

Incubated for $3 \mathrm{~h}$

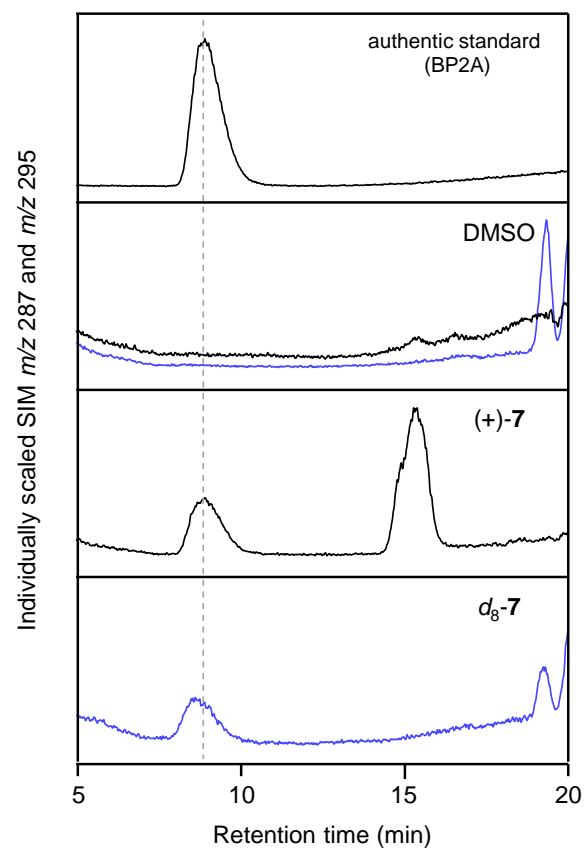

Incubated for $24 \mathrm{~h}$

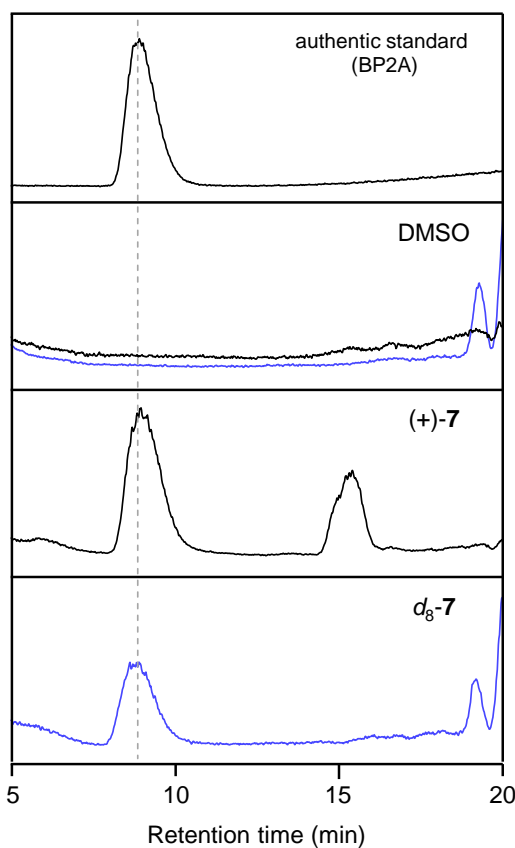

Incubated for $48 \mathrm{~h}$

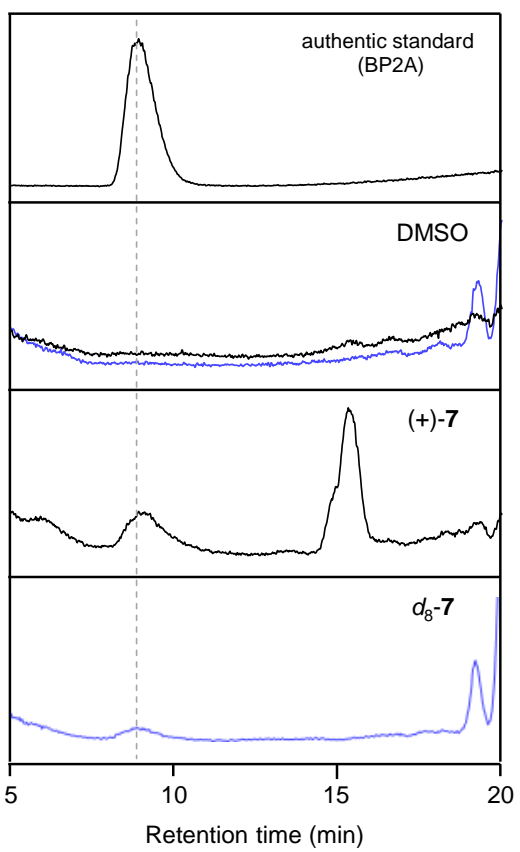

Figure S7 Representative LC-MS profile of $(+)-7(\mathrm{~m} / \mathrm{z} 322), d_{8}-7(\mathrm{~m} / \mathrm{z} 330),(+)-B P 2 A(\mathrm{~m} / z 287)$ and $d_{8}$-BP2A $(\mathrm{m} / \mathrm{z} 295)$ in Arabidopsis treated with DMSO, $(+)-7$ or $d_{8}-7$. Ten-day-old plants were treated with $25 \mu \mathrm{M}$ of $(+)-7$ or $d_{8}-7$ and incubated at $22{ }^{\circ} \mathrm{C}$ for 3 and $24 \mathrm{~h}$. After $24 \mathrm{~h}$, the plants were transferred to a water without $(+)-7 / d_{8}-7$ and incubated for a further $24 \mathrm{~h}$ (total $48 \mathrm{~h}$ incubation). Similar results were obtained in three independent experiments. 
$\begin{array}{ll}\text { ABA } & \square(+)-B P 2 A \quad \square(+)-7\end{array}$

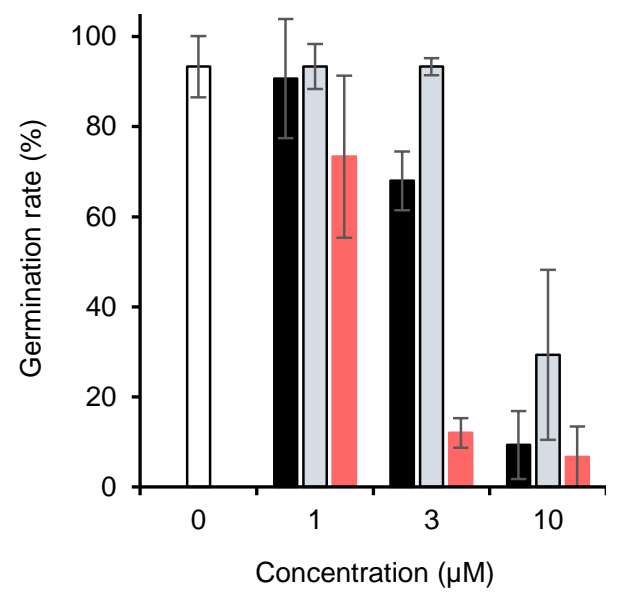

Figure S8 Effect of (+)-compound 7 on lettuce seed germination compared with that of $(+)$-BP2A. Seed germination rate in the presence of $(+)-7$, $(+)$-BP2A or ABA at $48 \mathrm{~h}(n=3$, error bars represent $S D s)$. 
(+)-7 $\square$ carboxylate form of $(+)-7$

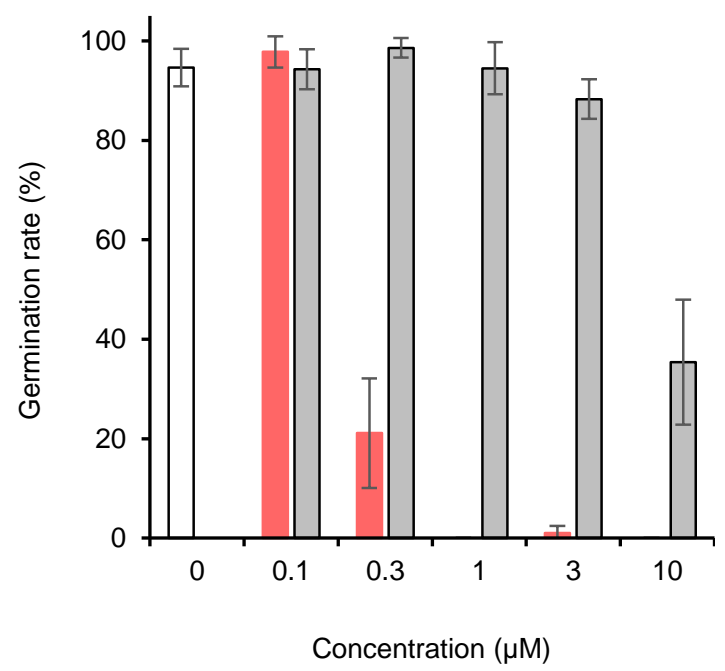

Figure S9 Effects of (+)-compound 7 and its carboxylate form, (+)-7', on Arabidopsis seed germination. Seed germination rate in the presence of $(+)-7$ or $(+)-7^{\prime}$ at $48 \mathrm{~h}(n=3$, error bars represent SDs). 


\section{Experimental}

\section{General procedures}

ABA was a gift from Dr. Y. Kamuro and Toray Industries Inc., Tokyo, Japan. ${ }^{1} \mathrm{H}$ NMR spectra were recorded with tetramethylsilane as the internal standard using JEOLJNM-EX270 (270 MHz) and JNMLA500 (500 MHz) NMR spectrometers (JEOL Ltd., Tokyo, Japan). All peak assignments refer to the numbering in structure ABA (Figure 1). High resolution mass spectra were obtained with a JEOL JMST100LC AccuTOF mass spectrometer (ESI-TOF, positive mode; JEOL Ltd.). Optical rotations were recorded with a Jasco DIP-1000 digital polarimeter. Circular dichroism spectra were recorded with a Jasco J-820 spectrophotometer. Column chromatography was performed using silica gel (Wakosil C-200, Wako P22ure Chemical Industries, Ltd.).

\section{Synthesis of $( \pm)$-BP2A and its analogs}

\section{1-Bromo-3-(2-(4-methoxyphenoxy)ethyl)benzene (11)}

4-Methoxy phenol (4.92 g, $39.6 \mathrm{mmol})$ and triphenylphosphine (10.4 g, $38.5 \mathrm{mmol})$ in THF (20 mL) was cooled to $0{ }^{\circ} \mathrm{C}$ under an atmosphere of Ar. Diethyl azodicarboxylate $(18 \mathrm{~mL}, 2.2 \mathrm{M})$ and a solution of 3bromophenethyl alcohol 10 (5.33 g, $26.5 \mathrm{mmol})$ in THF $(20 \mathrm{~mL})$ were added to the stirred mixture. The reaction mixture was stirred at room temperature for $5 \mathrm{~h}$. After quenching with sat. $\mathrm{NH}_{4} \mathrm{Cl}$ solution $(50$ $\mathrm{mL})$, it was extracted with EtOAc $(50 \mathrm{~mL} \times 3)$. The organic layer was washed with brine, dried over $\mathrm{Na}_{2} \mathrm{SO}_{4}$, and concentrated in vacuo. The residual oil was purified by silica gel chromatography with $10 \%$ EtOAc in hexane to obtain $11(3.12 \mathrm{~g}, 38 \%)$ as a yellow oil. ${ }^{1} \mathrm{H}$ NMR $\left(270 \mathrm{MHz}\right.$, acetone- $\left.d_{6}\right) \delta_{\mathrm{H}} 3.06$ $(2 \mathrm{H}, \mathrm{t}, J=6.9 \mathrm{~Hz}, \mathrm{ArCH}), 3.73\left(3 \mathrm{H}, \mathrm{s},-\mathrm{OCH}_{3}\right), 4.17\left(2 \mathrm{H}, \mathrm{t}, J=6.9 \mathrm{~Hz},-\mathrm{CH}_{2} \mathrm{OAr}\right), 6.85$ (4H, d, $J=1.6 \mathrm{~Hz}$, Ar), 7.23-7.42 (3H, m, Ar), 7.55 (1H, br s, Ar); ${ }^{13} \mathrm{C}$ NMR (125 MHz, $\left.\mathrm{CDCl}_{3}\right): \delta_{\mathrm{C}} 35.5,55.7,68.9,114.7$, $114.7,115.6,115.6,122.4,127.6,129.6,123.0,132.0,140.8,152.8,154.0$.

\section{8-(3-(2-(4-Methoxyphenoxy)ethyl)phenyl)-7,9,9-trimethyl-1,4-dioxaspiro[4.5]dec-6-en-8-ol (13)}

Compound $11(4.25 \mathrm{~g}, 13.8 \mathrm{mmol})$ in THF $(32 \mathrm{~mL})$ was cooled to $-78^{\circ} \mathrm{C}$ under an atmosphere of Ar. $N$, $N, N^{\prime}, N^{\prime}$-tetramethylenediamine $(6 \mathrm{~mL}, 39.8 \mathrm{mmol})$ and $n$-butyllithium $(13.5 \mathrm{~mL}, 20.9 \mathrm{mmol})$ was then added slowly. After being stirred for $5 \mathrm{~min}$ at $-78^{\circ} \mathrm{C}$, a solution of ketoacetal $12(3.29 \mathrm{~g}, 16.8 \mathrm{mmol})$ in dry THF $(32 \mathrm{~mL})$ was added dropwise to the mixture. The reaction mixture was stirred at $0{ }^{\circ} \mathrm{C}$ for $2 \mathrm{~h}$. After quenching with sat. $\mathrm{NH}_{4} \mathrm{Cl}$ solution $(60 \mathrm{~mL})$, it was extracted with EtOAc $(90 \mathrm{~mL} \times 3)$. The organic layer was washed with brine, dried over $\mathrm{Na}_{2} \mathrm{SO}_{4}$, and concentrated in vacuo. The residual oil was purified by silica gel chromatography with hexane-EtOAc stepwise to obtain $13(3.63 \mathrm{~g}, 62 \%)$ as a yellow oil. ${ }^{1} \mathrm{H}$ NMR (270 MHz, $\left.\mathrm{CD}_{3} \mathrm{OD}\right): \delta_{\mathrm{H}} 0.58\left(3 \mathrm{H}, \mathrm{s}, \mathrm{H}_{3}-8^{\prime}\right.$ or $\left.9^{\prime}\right), 1.17\left(3 \mathrm{H}, \mathrm{s}, \mathrm{H}_{3}-8^{\prime}\right.$ or $\left.9^{\prime}\right), 1.51(1 \mathrm{H}, \mathrm{dd}, J=14.2$ and 1.6 Hz, H-5'), $1.57\left(1 \mathrm{H}, \mathrm{d}, J=1.6 \mathrm{~Hz}, \mathrm{H}_{3}-7^{\prime}\right), 1.80\left(1 \mathrm{H}, \mathrm{d}, J=14.2 \mathrm{~Hz}, \mathrm{H}-5^{\prime}\right), 3.02(2 \mathrm{H}, \mathrm{t}, J=6.6 \mathrm{~Hz}$, $\left.\mathrm{H}_{2}-2\right), 3.72\left(3 \mathrm{H}, \mathrm{s},-\mathrm{OCH}_{3}\right), 3.85-4.17\left(6 \mathrm{H}, \mathrm{m},-\mathrm{OCH}_{2} \mathrm{CH}_{2} \mathrm{O}-\right.$ and $\left.\mathrm{H}_{2}-1\right), 5.59(1 \mathrm{H}, \mathrm{dq}, J=1.6$ and $1.6 \mathrm{~Hz}$, H-3'), 6.81 (4H, s, H-2" and H-3" and H-5" and H-6"), 7.15-7.39 (4H, m, H-4 and H-6 and H-7 and H- 
8); ${ }^{13} \mathrm{C}$ NMR (125 MHz, $\left.\mathrm{CDCl}_{3}\right): \delta_{\mathrm{C}} 18.5,24.3,25.8,36.0,38.9,44.5,55.7,63.9,64.6,69.4,81.2,105.1$, 114.6, 114.6, 115.6, 115.6, 124.9, 125.5, 127.6, 127.7, 128.1, 137.5, 140.6, 142.2,153.0, 153.8; HRMS $(\mathrm{m} / \mathrm{z}):[\mathrm{M}+\mathrm{Na}]^{+}$calcd. for $\mathrm{C}_{26} \mathrm{H}_{32} \mathrm{O}_{5} \mathrm{Na}, 447.2147$; found, 447.2144 .

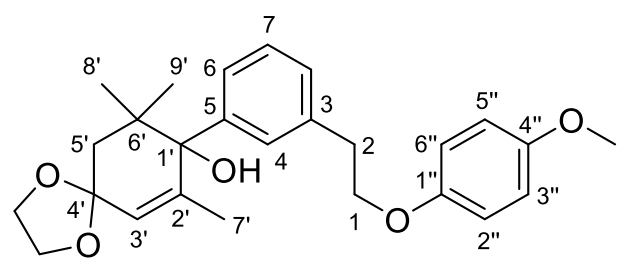

\section{1-Hydroxy-3'-(2-hydroxyethyl)-2,2,6-trimethyl-2,3-dihydro-[1,1'-biphenyl]-4(1H)-one (14)}

To a stirred solution of $\mathbf{1 3}(3.63 \mathrm{~g}, 8.5 \mathrm{mmol})$ in THF $(18 \mathrm{~mL})$ at $0{ }^{\circ} \mathrm{C}$ was added an aqueous solution of ammonium cerium nitrate $(1.47 \mathrm{~g}, 24.7 \mathrm{mmol})$. The reaction mixture was stirred for $3.5 \mathrm{~h}$ at room temperature, and then added water $(12 \mathrm{~mL})$ and extracted with EtOAc $(50 \mathrm{~mL} \times 3)$. The organic layer was washed with sat. $\mathrm{NaHCO}_{3}$ solution and brine, dried over $\mathrm{Na}_{2} \mathrm{SO}_{4}$, and concentrated in vacuo. The residual oil was purified by silica gel chromatography with 60\% EtOAc in hexane to obtain $14(1.79 \mathrm{~g}$, $77 \%$ ) as a brown oil. ${ }^{1} \mathrm{H}$ NMR (270 MHz, $\left.\mathrm{CD}_{3} \mathrm{OD}\right): \delta_{\mathrm{H}} 0.73\left(3 \mathrm{H}, \mathrm{s}, \mathrm{H}_{3}-8^{\prime}\right.$ or $\left.9^{\prime}\right), 1.16$ (3H, s, $\mathrm{H}_{3}-8^{\prime}$ or $\left.9^{\prime}\right)$, $1.83\left(3 \mathrm{H}, \mathrm{d}, J=1.0 \mathrm{~Hz}, \mathrm{H}_{3}-7^{\prime}\right), 2.07$ (1H, dd, $J=16.8$ and $\left.1.0 \mathrm{~Hz}, \mathrm{H}-5^{\prime}\right), 2.35$ (1H, d, $\left.J=16.8 \mathrm{~Hz}, \mathrm{H}-5^{\prime}\right)$, $2.83\left(2 \mathrm{H}, \mathrm{t}, J=6.9 \mathrm{~Hz}, \mathrm{H}_{2}-2\right), 3.74\left(2 \mathrm{H}, \mathrm{dt}, J=6.9\right.$ and $\left.0.6 \mathrm{~Hz}, \mathrm{H}_{2}-1\right), 6.12(1 \mathrm{H}, \mathrm{dq}, J=1.0$ and $1.0 \mathrm{~Hz}, \mathrm{H}-$ 3'), 7.16-7.20 (3H, m, H-6 and H-7 and H-8), 7.34 (1H, br s, H-4); ${ }^{13} \mathrm{C}$ NMR (68 MHz, $\mathrm{CDCl}_{3}$ ): $\delta_{\mathrm{C}} 19.5$, 24.2, 25.1, 39.3, 41.5, 49.6, 63.7, 77.2, 81.6, 124.9, 127.6, 128.2, 128.6, 138.5, 139.1, 162.1, 198.8; HRMS (m/z): $[\mathrm{M}+\mathrm{Na}]^{+}$calcd. for $\mathrm{C}_{17} \mathrm{H}_{22} \mathrm{O}_{3} \mathrm{Na}, 297.1467$; found, 297.1474 .

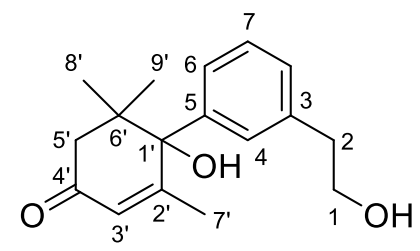

2-(1'-Hydroxy-2',2',6'-trimethyl-4'-oxo-1',2',3',4'-tetrahydro-[1,1'-biphenyl]-3-yl)acetic acid, ( \pm )BP2A (5)

To a two-phase mixture of $\mathbf{1 4}(1.78 \mathrm{~g}, 6.48 \mathrm{mmol})$ in $\mathrm{CH}_{2} \mathrm{Cl}_{2}(18 \mathrm{~mL})$ and $1.0 \mathrm{M}$ sodium acetate buffer $(\mathrm{pH} 4.0,18 \mathrm{~mL})$ was added $\mathrm{NaClO}_{2}(2.20 \mathrm{~g}, 19.4 \mathrm{mmol})$ and catalytic amount of AZADOL ${ }^{\circledR}(49.1 \mathrm{mg}$, $0.32 \mathrm{mmol}$ ), and the mixture was stirred for $4 \mathrm{~h}$ at room temperature. Then, 2-methyl-2-butene $(3.5 \mathrm{~mL})$ and water $(10 \mathrm{~mL})$ were added to the reaction mixture. After being adjusted the $\mathrm{pH}$ to 9 with sat. $\mathrm{NaHCO}_{3}$ solution, the reaction mixture was washed with $\mathrm{CH}_{2} \mathrm{Cl}_{2}(30 \mathrm{~mL} \times 3)$. The aqueous phase was then acidified with $1 \mathrm{M} \mathrm{HCl}$ to $\mathrm{pH} 2$ and extracted with $\mathrm{CH}_{2} \mathrm{Cl}_{2}(100 \mathrm{~mL} \times 3)$. The organic phase was washed with brine, dried over $\mathrm{Na}_{2} \mathrm{SO}_{4}$, and concentrated in vacuo. The residual solid was purified by silica gel 
chromatography with $80 \%$ EtOAc in hexane containing $0.1 \% \mathrm{AcOH}$ to obtain $( \pm)-\mathbf{B P 2 A}(1.34 \mathrm{~g}, 72 \%)$ as a white solid, which was further purified for bioassays by HPLC (YMC Hydrosphere C18, $150 \times 20$ mm i.d.; solvent, $50 \% \mathrm{MeOH}$ in $\mathrm{H}_{2} \mathrm{O}$ containing $0.1 \% \mathrm{AcOH}$; flow rate, $8 \mathrm{~mL} \mathrm{~min}^{-1}$; detection, $254 \mathrm{~nm}$ ). ${ }^{1} \mathrm{H}$ NMR (270 MHz, $\left.\mathrm{CD}_{3} \mathrm{OD}\right): \delta_{\mathrm{H}} 0.72\left(3 \mathrm{H}, \mathrm{s}, \mathrm{H}_{3}-8^{\prime}\right.$ or $\left.9^{\prime}\right), 1.15\left(3 \mathrm{H}, \mathrm{s}, \mathrm{H}_{3}-8^{\prime}\right.$ or $\left.9^{\prime}\right), 1.84(3 \mathrm{H}, \mathrm{d}, J=1.3$ $\left.\mathrm{Hz}, \mathrm{H}_{3}-7^{\prime}\right), 2.07\left(1 \mathrm{H}, \mathrm{dd}, J=16.8\right.$ and $\left.1.3 \mathrm{~Hz}, \mathrm{H}-5^{\prime}\right), 2.35$ (1H, d, $\left.J=16.8 \mathrm{~Hz}, \mathrm{H}-5^{\prime}\right), 3.62\left(2 \mathrm{H}, \mathrm{s}, \mathrm{H}_{2}-2\right)$, $6.13\left(1 \mathrm{H}, \mathrm{dq}, J=1.3\right.$ and $\left.1.3 \mathrm{~Hz}, \mathrm{H}-3^{\prime}\right), 7.21-7.40$ (3H, m, H-6 and $\mathrm{H}-7$ and $\left.\mathrm{H}-8\right), 7.34(1 \mathrm{H}, \mathrm{br} \mathrm{s}, \mathrm{H}-4) ;{ }^{13} \mathrm{C}$ NMR (68 MHz, $\left.\mathrm{CD}_{3} \mathrm{OD}\right): \delta_{\mathrm{C}} 20.1,24.7,25.6,42.0,42.6,50.6,82.1,126.9,128.6,128.9,129.5,129.7$, 135.7, 141.0, 166.5, 173.5, 201.8; HRMS $(\mathrm{m} / \mathrm{z})$ : $[\mathrm{M}+\mathrm{Na}]^{+}$calcd. for $\mathrm{C}_{17} \mathrm{H}_{20} \mathrm{O}_{4} \mathrm{Na}, 311.1259$; found, 311.1261.

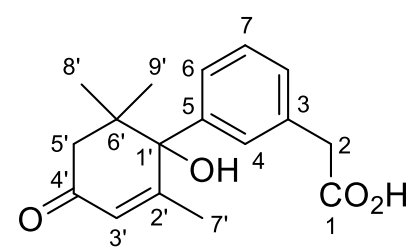

A CHIRAL ART Cellulose-SC HPLC column (YMC, $250 \times 10 \mathrm{~mm}$ i.d.; solvent, $65 \% \mathrm{CHCl}_{3}$ in hexane containing $0.1 \% \mathrm{AcOH}$; flow rate, $4.0 \mathrm{~mL} \mathrm{~min}^{-1}$; detection, $\left.254 \mathrm{~nm}\right)$ was infected with $( \pm)$-BP2A. The material at $t_{\mathrm{R}} 21.3$ and $23.3 \mathrm{~min}$ were collected to give (-)-BP2A (4.1 mg) and the (+)-enantiomer (3.5 $\mathrm{mg}$ ) with an optical purity of $99.9 \%$ and $99.9 \%$, respectively. $(+)-\mathrm{BP} 2 \mathrm{~A}:[\alpha]_{\mathrm{D}}^{28}+172.3(\mathrm{MeOH} ; c 2.55 \times$ $\left.10^{-3}\right)$; $\mathrm{CD} \lambda_{\text {ext }}(\mathrm{MeOH}) \mathrm{nm}(\Delta \varepsilon): 228.0(23.4), 203.0(-4.3)$. (-)-BP2A: $[\alpha]_{\mathrm{D}}^{28}-168.9(\mathrm{MeOH} ; c 2.14 \times$ $\left.10^{-3}\right) ; \mathrm{CD} \lambda_{\text {ext }}(\mathrm{MeOH}) \mathrm{nm}(\Delta \varepsilon): 228.0(-25.7), 204.0(3.6)$.

\section{Methyl ( \pm )-BP2A (5a)}

To a stirred solution of 5 (200 mg, $0.69 \mathrm{mmol})$ in THF $(1 \mathrm{~mL})$ at $0{ }^{\circ} \mathrm{C}$ was added DMF (5 drops) and oxalyl chloride $(0.15 \mathrm{~mL}, 1.7 \mathrm{mmol})$. The reaction mixture was stirred for $30 \mathrm{~min}$ at room temperature, then $\mathrm{MeOH}(2 \mathrm{~mL})$ was added and the mixture was stirred for extra $10 \mathrm{~min}$. The $\mathrm{pH}$ of the mixture was adjusted to 9 using sat. $\mathrm{NaHCO}_{3}$ solution, it was extracted with EtOAc $(10 \mathrm{~mL} \times 3)$. The organic layer was washed with brine, dried over $\mathrm{Na}_{2} \mathrm{SO}_{4}$, and concentrated in vacuo. The residual oil was purified by silica gel chromatography with $35 \%$ EtOAc in hexane to obtain $\mathbf{5 a}$ (220 mg, quantitative yield) as a colorless oil. ${ }^{1} \mathrm{H}$ NMR $\left(270 \mathrm{MHz}, \mathrm{CDCl}_{3}\right)$ : $\delta_{\mathrm{H}} 0.77\left(3 \mathrm{H}, \mathrm{s}, \mathrm{H}_{3}-8^{\prime}\right.$ or 9'), $1.21\left(3 \mathrm{H}, \mathrm{s}, \mathrm{H}_{3}-8^{\prime}\right.$ or $\left.9^{\prime}\right), 1.84(3 \mathrm{H}$, d, $\left.J=1.0 \mathrm{~Hz}, \mathrm{H}_{3}-7^{\prime}\right), 2.13\left(1 \mathrm{H}, \mathrm{dd}, J=16.8 \mathrm{~Hz}, \mathrm{H}-5^{\prime}\right), 2.36\left(1 \mathrm{H}, \mathrm{d}, J=16.8 \mathrm{~Hz}, \mathrm{H}-5^{\prime}\right), 3.65\left(2 \mathrm{H}, \mathrm{s}, \mathrm{H}_{2}-2\right)$, $3.69\left(3 \mathrm{H}, \mathrm{s},-\mathrm{OCH} \mathrm{H}_{3}\right), 6.17$ (1H, br s, H-3'), 7.22-7.38 (4H, m, H-4, H-6, H-7 and H-8); HRMS $(m / z)$ : $[\mathrm{M}+\mathrm{Na}]^{+}$calcd. for $\mathrm{C}_{18} \mathrm{H}_{22} \mathrm{O}_{4} \mathrm{Na}, 325.1416$; found 325.1439 .

\section{Methyl $\left(1^{\prime} R^{*}, 2^{\prime} S^{*}\right)-( \pm)-2^{\prime}, 3^{\prime}$-dihydro-4'-hydroxy-BP2A (15)}

To a stirred solution of 5a (104 mg, $0.344 \mathrm{mmol})$ in dry THF $(3.5 \mathrm{~mL})$ was added $\mathrm{NaBH}_{4}(96 \mathrm{mg}, 2.4$ $\mathrm{mmol}$ ), and the mixture was stirred for $25 \mathrm{~h}$ at room temperature. After quenching with sat. $\mathrm{NH}_{4} \mathrm{Cl}$ 
solution $(8 \mathrm{~mL})$, it was extracted with EtOAc $(10 \mathrm{~mL} \times 3)$. The organic layer was washed with brine, dried over $\mathrm{Na}_{2} \mathrm{SO}_{4}$, and concentrated in vacuo. The residual oil was purified by silica gel chromatography with hexane/toluene/EtOAc (4/3/4, v/v/v) to obtain 15 (37.8 mg, 36\%) as a colorless oil. Data of 15 (1:1 diastereomeric mixture at $\mathrm{C}^{\prime}$ and $\left.\mathrm{C}^{\prime}\right) .{ }^{1} \mathrm{H}$ NMR $\left(270 \mathrm{MHz}, \mathrm{CDCl}_{3}\right): \delta_{\mathrm{H}} 0.57\left(3 \mathrm{H}, \mathrm{s}, \mathrm{H}_{3}-8^{\prime}\right.$ or $\left.9^{\prime}\right), 0.68$ $\left(3 \mathrm{H}, \mathrm{d}, J=6.6 \mathrm{~Hz}, \mathrm{H}_{3}-7^{\prime}\right), 1.20\left(3 \mathrm{H}, \mathrm{s}, \mathrm{H}_{3}-8^{\prime}\right.$ or $\left.9^{\prime}\right), 1.54-1.80\left(2 \mathrm{H}, \mathrm{m}, \mathrm{H}-3^{\prime}\right.$ and $\left.\mathrm{H}-5^{\prime}\right), 1.84-2.07(2 \mathrm{H}, \mathrm{m}$, $\mathrm{H}-3^{\prime}$ and $\left.\mathrm{H}-5^{\prime}\right), 2.18$ and $2.22\left(1 \mathrm{H}, \mathrm{tq}, J=6.6\right.$ and $\left.6.6 \mathrm{~Hz}, \mathrm{H}-2^{\prime}\right), 3.65\left(2 \mathrm{H}, \mathrm{s}, \mathrm{H}_{2}-2\right), 3.69\left(3 \mathrm{H}, \mathrm{s},-\mathrm{OCH}_{3}\right)$, 4.15 and $4.19\left(1 \mathrm{H}, \mathrm{tt}, J=5.6\right.$ and $\left.5.6 \mathrm{~Hz}, \mathrm{H}-4^{\prime}\right), 7.15(1 \mathrm{H}, \mathrm{m}, \mathrm{H}-8), 7.27(1 \mathrm{H}, \mathrm{m}, \mathrm{H}-7), 7.56(1 \mathrm{H}, \mathrm{m}, \mathrm{H}-6)$, $7.61(1 \mathrm{H}, \mathrm{m}, \mathrm{H}-4)$; HRMS $(\mathrm{m} / \mathrm{z})$ : $[\mathrm{M}+\mathrm{Na}]^{+}$calcd. for $\mathrm{C}_{18} \mathrm{H}_{26} \mathrm{O}_{4} \mathrm{Na}, 329.1729$; found, 329.1756 .

\section{Methyl $\left(1^{\prime} R^{*}, 2^{\prime} S^{*}\right)-( \pm)-2^{\prime}, 3^{\prime}$-dihydro-BP2A (6)}

A mixture of pyridinium dichromate $(320 \mathrm{mg}, 0.85 \mathrm{mmol})$ and Celite ${ }^{\circledR}(170 \mathrm{mg})$ was wetted with $\mathrm{CH}_{2} \mathrm{Cl}_{2}$ $(1 \mathrm{~mL})$ and added a solution of $\mathbf{1 5}(100 \mathrm{mg}, 0.33 \mathrm{mmol})$ in dry $\mathrm{CH}_{2} \mathrm{Cl}_{2}(1.5 \mathrm{~mL})$. The mixture was stirred for $5 \mathrm{~h}$ at room temperature, filtered with Celite ${ }^{\circledR}$, and eluted with $\mathrm{CH}_{2} \mathrm{Cl}_{2}$. The eluate was concentrated in vacuo. The residual oil was purified by silica gel chromatography with hexane-EtOAc stepwise to obtain 6 (44 mg, 44\%) as a colorless oil. ${ }^{1} \mathrm{H}$ NMR $\left(270 \mathrm{MHz}, \mathrm{CDCl}_{3}\right): \delta_{\mathrm{H}} 0.59\left(3 \mathrm{H}, \mathrm{s}, \mathrm{H}_{3}-8^{\prime}\right.$ or $\left.9^{\prime}\right), 0.83$ $\left(3 \mathrm{H}, \mathrm{d}, J=6.3 \mathrm{~Hz}, \mathrm{H}_{3}-7^{\prime}\right), 1.18$ ( $3 \mathrm{H}, \mathrm{s}, \mathrm{H}_{3}-8^{\prime}$ or $\left.9^{\prime}\right), 2.14\left(1 \mathrm{H}, \mathrm{dd}, J=15.5\right.$ and $\left.1.3 \mathrm{~Hz}, \mathrm{H}-5^{\prime}\right), 2.50-2.70$ (3H, m, H-2' and $\left.\mathrm{H}_{2}-3^{\prime}\right), 2.78\left(1 \mathrm{H}, \mathrm{d}, J=15.5 \mathrm{~Hz}, \mathrm{H}-5^{\prime}\right), 3.66\left(2 \mathrm{H}, \mathrm{s}, \mathrm{H}_{2}-2\right), 3.69\left(3 \mathrm{H}, \mathrm{s},-\mathrm{OCH}_{3}\right), 7.21(1 \mathrm{H}, \mathrm{m}$, $\mathrm{H}-8), 7.32$ (1H, dd, $J=7.6$ and $7.6 \mathrm{~Hz}, \mathrm{H}-7), 7.46(1 \mathrm{H}, \mathrm{m}, \mathrm{H}-6), 7.54(1 \mathrm{H}, \mathrm{m}, \mathrm{H}-4) ;{ }^{13} \mathrm{C}$ NMR $(125 \mathrm{MHz}$, $\left.\mathrm{CDCl}_{3}\right): \delta_{\mathrm{C}} 16.2,24.3,25.6,39.2,41.3,41.9,47.5,52.0,52.6,79.0,126.1,127.9,128.0,128.6,133.6$, 142.2, 171.9, 210.3; HRMS (m/z): $[\mathrm{M}+\mathrm{Na}]^{+}$calcd. for $\mathrm{C}_{18} \mathrm{H}_{24} \mathrm{O}_{4} \mathrm{Na}$, 327.1572; found, 327.1587 .

\section{Methyl $\left(1^{\prime} S^{*}, 4^{\prime} S^{*}\right)-( \pm)-1^{\prime}, 4^{\prime}-$ trans-diol-BP2A (7)}

To a stirred solution of $5 \mathbf{a}(220 \mathrm{mg}, 0.73 \mathrm{mmol})$ in $\mathrm{MeOH}(5 \mathrm{~mL})$ at $0{ }^{\circ} \mathrm{C}$ was added cerium (III) chloride heptahydrate (788 mg, $2.12 \mathrm{mmol})$ and $\mathrm{NaHB}_{4}(61 \mathrm{mg}, 1.6 \mathrm{mmol})$. The reaction mixture was stirred for $30 \mathrm{~min}$ at $0{ }^{\circ} \mathrm{C}$, and then quenched with sat. $\mathrm{NH}_{4} \mathrm{Cl}$ solution $(20 \mathrm{~mL})$ and extracted with EtOAc $(20 \mathrm{~mL}$ $\times 3$ ). The organic layer was washed with water and brine, dried over $\mathrm{Na}_{2} \mathrm{SO}_{4}$, and concentrated in vacuo. The residual oil was purified by silica gel chromatography with 40\% EtOAc in hexane to obtain 7 (143 $\mathrm{mg}, 64 \%)$ as a colorless oil. ${ }^{1} \mathrm{H} \mathrm{NMR}\left(500 \mathrm{MHz}, \mathrm{CDCl}_{3}\right)$ : $\delta_{\mathrm{H}} 0.63\left(3 \mathrm{H}, \mathrm{s}, \mathrm{H}_{3}-8^{\prime}\right.$ or $\left.9^{\prime}\right), 1.15\left(3 \mathrm{H}, \mathrm{s}, \mathrm{H}_{3}-8^{\prime}\right.$ or $\left.9^{\prime}\right), 1.50\left(1 \mathrm{H}, \mathrm{dd}, J=13.1\right.$ and $\left.9.8 \mathrm{~Hz}, \mathrm{H}-5^{\prime}\right), 1.58\left(3 \mathrm{H}, \mathrm{dd}, J=1.8\right.$ and $\left.1.5 \mathrm{~Hz}, \mathrm{H}_{3}-7^{\prime}\right), 1.66(1 \mathrm{H}$, ddd, $J=13.2,6.7$ and $\left.1.5 \mathrm{~Hz}, \mathrm{H}-5^{\prime}\right), 3.65\left(2 \mathrm{H}, \mathrm{s}, \mathrm{H}_{2}-2\right), 3.69\left(3 \mathrm{H}, \mathrm{s},-\mathrm{OCH}_{3}\right), 4.37\left(1 \mathrm{H}, \mathrm{m}, \mathrm{H}-4^{\prime}\right), 5.80(1 \mathrm{H}, \mathrm{m}$, $\left.\mathrm{H}-3^{\prime}\right), 7.16$ (1H, m, H-8), 7.28 (dd, $J=7.6$ and 7.6 Hz, H-7), 7.40-7.47 (2H, m, H-4 and H-6); ${ }^{13} \mathrm{C} \mathrm{NMR}$ $\left(125 \mathrm{MHz}, \mathrm{CDCl}_{3}\right): \delta_{\mathrm{C}} 18.4,23.5,25.9,39.7,41.0,43.3,52.0,65.7,81.2,126.4,127.5,127.9,128.3$, 128.6, 132.9, 138.6, 142.0, 172.2 ;HRMS $(m / z):[\mathrm{M}+\mathrm{Na}]^{+}$calcd. for $\mathrm{C}_{18} \mathrm{H}_{24} \mathrm{O}_{4} \mathrm{Na}, 327.1572$; found, 325.1595 .

\section{Methyl (1'S,4'S)-(+)-1',4'-diol-BP2A, (+)-7}


Methyl (+)-BP2A (22.7 mg, $75 \mu \mathrm{mol})$ was converted to Me (1'S,4'S)-(+)-1',4'-diol-BP2A (9.7 mg, 32 $\mu \mathrm{mol}, 42 \%)$ by the same manner. $[\alpha]_{\mathrm{D}}^{23}+154(\mathrm{MeOH} ; c 0.090)$

\section{Methyl $\left(1^{\prime} S^{*}, 4^{\prime} S^{\star}\right)-( \pm)-4^{\prime}-O$-formyl-BP2A (8)}

The mixture of formic acid $(0.1 \mathrm{~mL})$ and acetic anhydride $(0.2 \mathrm{~mL})$ was stirred for $1 \mathrm{~h}$ at $60{ }^{\circ} \mathrm{C}$, and then cooled to room temperature. Methyl 1',4'-trans-diol-BP2A (7) (68.5 mg, $0.23 \mathrm{mmol})$ and $\mathrm{NaHCO}_{3}(48.5$ $\mathrm{mg}, 0.58 \mathrm{mmol}$ ) were added to the mixture and stirred for $1 \mathrm{~h}$ at room temperature. After quenching with water $(4 \mathrm{~mL})$, it was extracted with EtOAc $(10 \mathrm{~mL} \times 3)$. The organic layer was washed with water and brine, dried over $\mathrm{Na}_{2} \mathrm{SO}_{4}$, and concentrated in vacuo. The residual oil was purified by silica gel chromatography with $20 \%$ EtOAc in hexane to obtain 8 (63 mg, 85\%) as a colorless oil. ${ }^{1} \mathrm{H}$ NMR (500 $\left.\mathrm{MHz}, \mathrm{CDCl}_{3}\right): \delta_{\mathrm{H}} 0.65\left(3 \mathrm{H}, \mathrm{s}, \mathrm{H}_{3}-8^{\prime}\right.$ or $\left.9^{\prime}\right), 1.20\left(3 \mathrm{H}, \mathrm{s}, \mathrm{H}_{3}-8^{\prime}\right.$ or $\left.9^{\prime}\right), 1.60\left(3 \mathrm{H}, \mathrm{dd}, J=1.8\right.$ and $1.5 \mathrm{~Hz}, \mathrm{H}_{3}-$ 7'), $1.67\left(1 \mathrm{H}, \mathrm{dd}, J=13.1\right.$ and $\left.9.5 \mathrm{~Hz}, \mathrm{H}-5^{\prime}\right), 1.73\left(1 \mathrm{H}, \mathrm{ddd}, J=13.1,7.0\right.$ and $\left.1.2 \mathrm{~Hz}, \mathrm{H}-5^{\prime}\right), 1.88(1 \mathrm{H}, \mathrm{s},-$ $\mathrm{OH}), 3.66\left(2 \mathrm{H}, \mathrm{s}, \mathrm{H}_{2}-2\right), 3.69\left(3 \mathrm{H}, \mathrm{s},-\mathrm{OCH}_{3}\right), 5.60\left(1 \mathrm{H}, \mathrm{m}, \mathrm{H}-4^{\prime}\right), 5.73(1 \mathrm{H}, \mathrm{m}, \mathrm{H}-3$ '), 7.20 (d, J=7.3 Hs, $\mathrm{H}-8$ ), 7.29 (dd, $J=7.6$ and 7.6 Hz, H-7), 7.33-7.50 (2H, m, H-6 and H-4), 8.14 (1H, d, $J=0.9 \mathrm{~Hz},-\mathrm{OCHO}$ ); ${ }^{13} \mathrm{C}$ NMR $\left(125 \mathrm{MHz}, \mathrm{CDCl}_{3}\right)$ : $\delta_{\mathrm{C}} 18.5,23.4,25.8,38.9,39.5,41.3,52.0,69.0,80.7,123.2,126.3,127.7$, 128.2, 128.6, 133.3, 141.8, 141.8, 161.0, $172.1 ; \operatorname{HRMS}(m / z):[\mathrm{M}+\mathrm{Na}]^{+}$calcd. for $\mathrm{C}_{19} \mathrm{H}_{4} \mathrm{O}_{5} \mathrm{Na}, 355.1521$; found, 355.1543 .

\section{Methyl (1'S,4'S)-(+)-4'-O-formyl-BP2A, (+)-8}

Compound (+)-7 (3.0 mg, $9.8 \mu \mathrm{mol})$ was converted to Me (1'S,4'S)-(+)-4'-O-formyl-BP2A (2.5 mg, 7.5 $\mu \mathrm{mol}, 80 \%)$ by the same manner. $[\alpha]_{\mathrm{D}}^{23}+100(\mathrm{MeOH} ; c 0.11)$

\section{Methyl (1' $\left.S^{*}, \mathbf{4}^{\prime} S^{*}\right)-( \pm)-4^{\prime}-O$-acetyl-BP2A (9)}

$( \pm)$-Compound $7(28.2 \mathrm{mg}, 0.093 \mathrm{mmol})$ was dissolved in a 1:2 (v/v) mixture of acetic anhydride and pyridine $(1 \mathrm{~mL})$, and then stirred for $45 \mathrm{~min}$ at $40{ }^{\circ} \mathrm{C}$. After quenching with $1 \mathrm{M} \mathrm{HCl}$, it was extracted with EtOAc $(20 \mathrm{~mL} \times 3)$. The organic layer was washed with $1 \mathrm{M} \mathrm{HCl}$ and brine, dried over $\mathrm{Na}_{2} \mathrm{SO}_{4}$, and concentrated in vacuo. The residual oil was purified by silica gel chromatography with $20 \%$ EtOAc in hexane to obtain $9(27.8 \mathrm{mg}, 86 \%)$ as a colorless oil. ${ }^{1} \mathrm{H}$ NMR $\left(500 \mathrm{MHz}, \mathrm{CDCl}_{3}\right): \delta_{\mathrm{H}} 0.63\left(3 \mathrm{H}, \mathrm{s}, \mathrm{H}_{3^{-}}\right.$ $8^{\prime}$ or $\left.9^{\prime}\right), 1.19\left(3 \mathrm{H}, \mathrm{s}, \mathrm{H}_{3}-8^{\prime}\right.$ or $\left.9^{\prime}\right), 1.58\left(3 \mathrm{H}, \mathrm{dd}, J=1.5\right.$ and $\left.1.5 \mathrm{~Hz}, \mathrm{H}_{3}-7^{\prime}\right), 1.63(1 \mathrm{H}, \mathrm{dd}, J=13.1$ and 9.8 $\left.\mathrm{Hz}, \mathrm{H}-5^{\prime}\right), 1.70\left(1 \mathrm{H}\right.$, ddd, $J=13.1,6.4$ and $\left.1.2 \mathrm{~Hz}, \mathrm{H}-5^{\prime}\right), 1.88(1 \mathrm{H}, \mathrm{s},-\mathrm{OH}), 2.11\left(3 \mathrm{H}, \mathrm{s},-\mathrm{OCOCH}_{3}\right), 3.66$ $\left(2 \mathrm{H}, \mathrm{s}, \mathrm{H}_{2}-2\right), 3.69$ (3H, s, -COOCH 3$), 5.64\left(1 \mathrm{H}, \mathrm{m}, \mathrm{H}-4^{\prime}\right), 5.72\left(1 \mathrm{H}, \mathrm{m}, \mathrm{H}-3^{\prime}\right), 7.20$ (dd, J=7.9 Hs, H-8), 7.29 (dd, $J=7.9$ and $7.9 \mathrm{~Hz}, \mathrm{H}-7), 7.31-7.45\left(2 \mathrm{H}, \mathrm{m}, \mathrm{H}-6\right.$ and H-4); ${ }^{13} \mathrm{C} \mathrm{NMR}\left(125 \mathrm{MHz}, \mathrm{CDCl}_{3}\right): \delta_{\mathrm{C}}$ 18.5, 21.4, 23.5, 25.8, 39.0, 39.5, 41.3, 52.0, 69.0, 80.9, 124.0, 126.3, 127.6, 128.0, 128.6 133.2, 141.0, 142.0, 171.0, 172.1;HRMS (m/z): [M+Na $]^{+}$calcd. for $\mathrm{C}_{20} \mathrm{H}_{26} \mathrm{O}_{5} \mathrm{Na}, 369.1678$; found, 369.1690 . 
3) ${ }^{1} \mathrm{H}$ and ${ }^{13} \mathrm{C}$ NMR Spectrums of Synthesized Compounds

${ }^{1} \mathrm{H}$ NMR spectrum of Compound 11
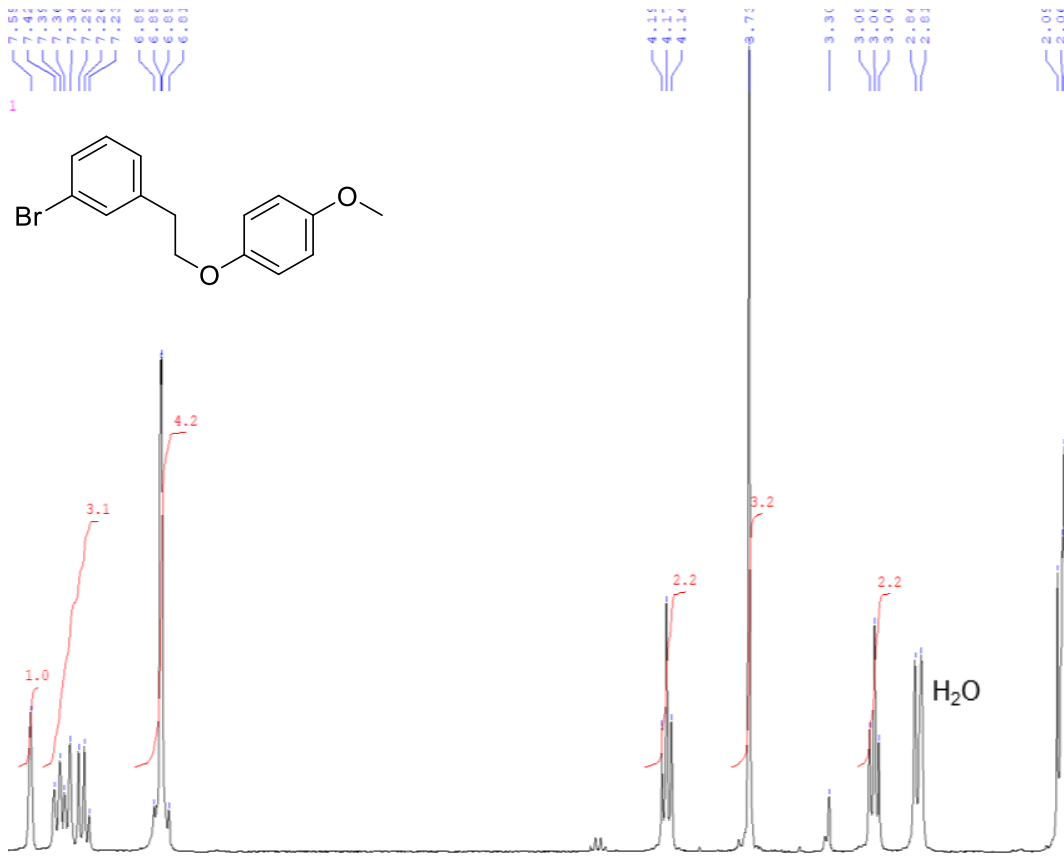

${ }^{13} \mathrm{C}$ NMR spectrum of Compound 11

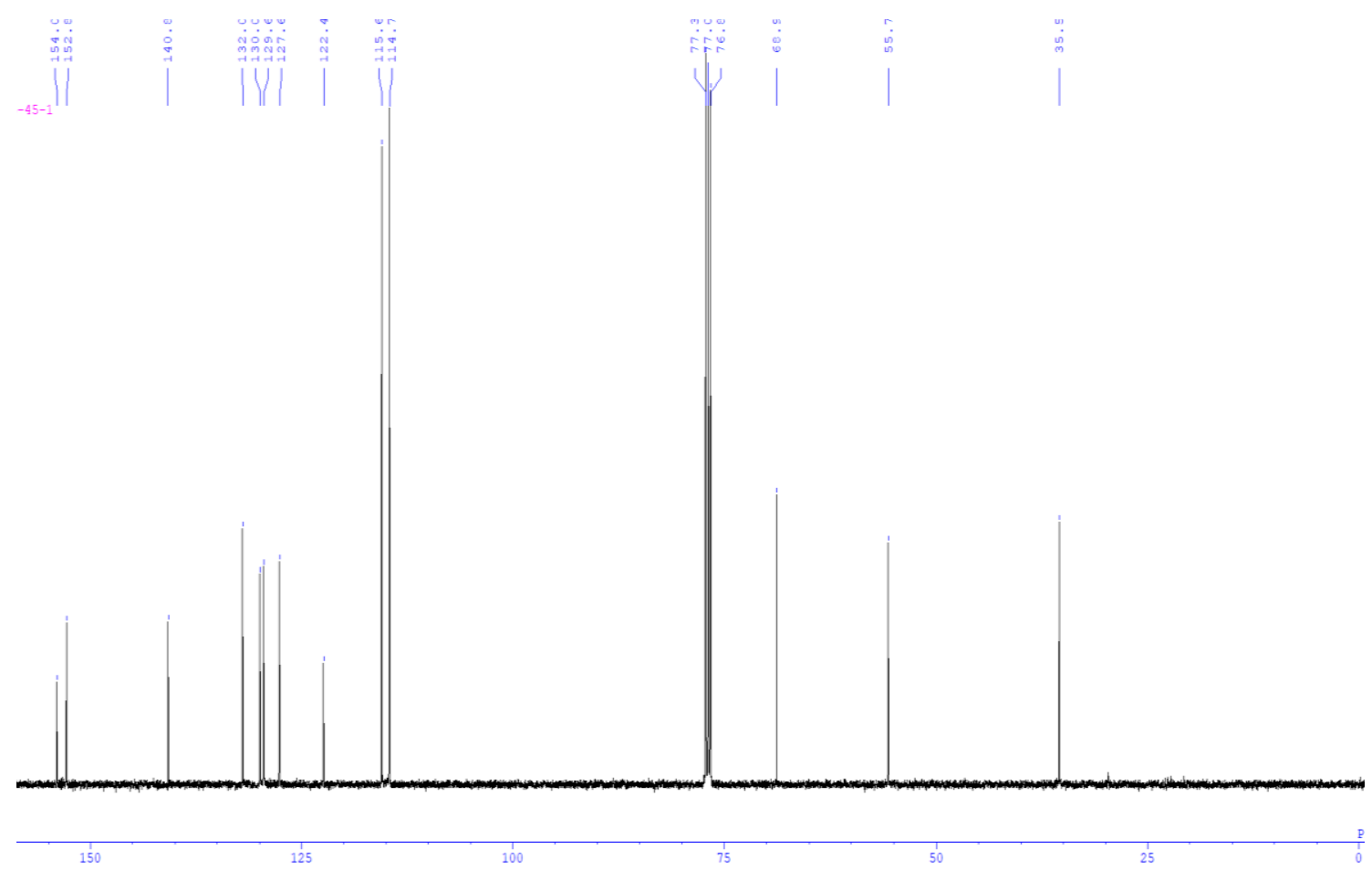


${ }^{1} \mathrm{H}$ NMR spectrum of Compound 13

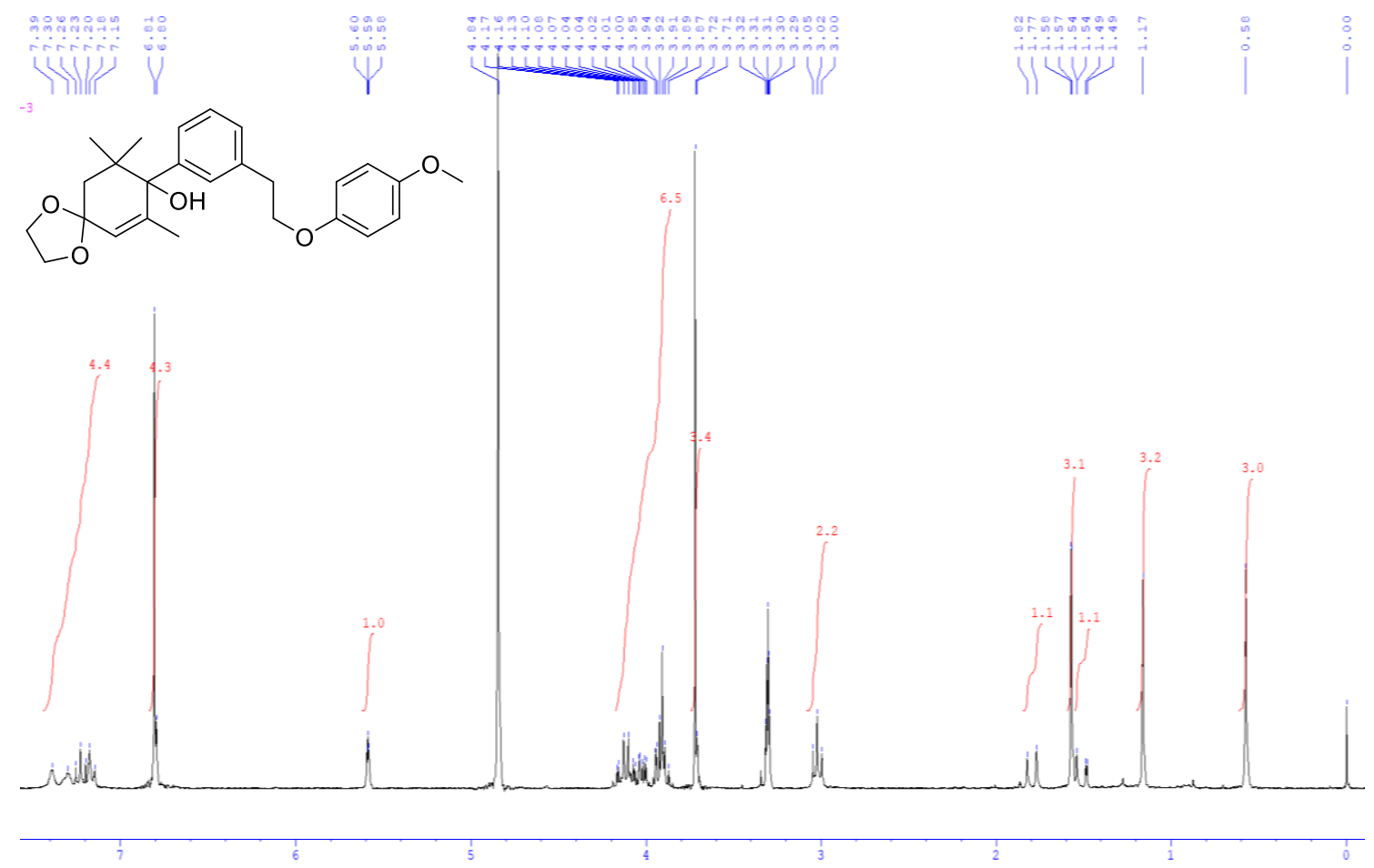

${ }^{13} \mathrm{C}$ NMR spectrum of Compound 13

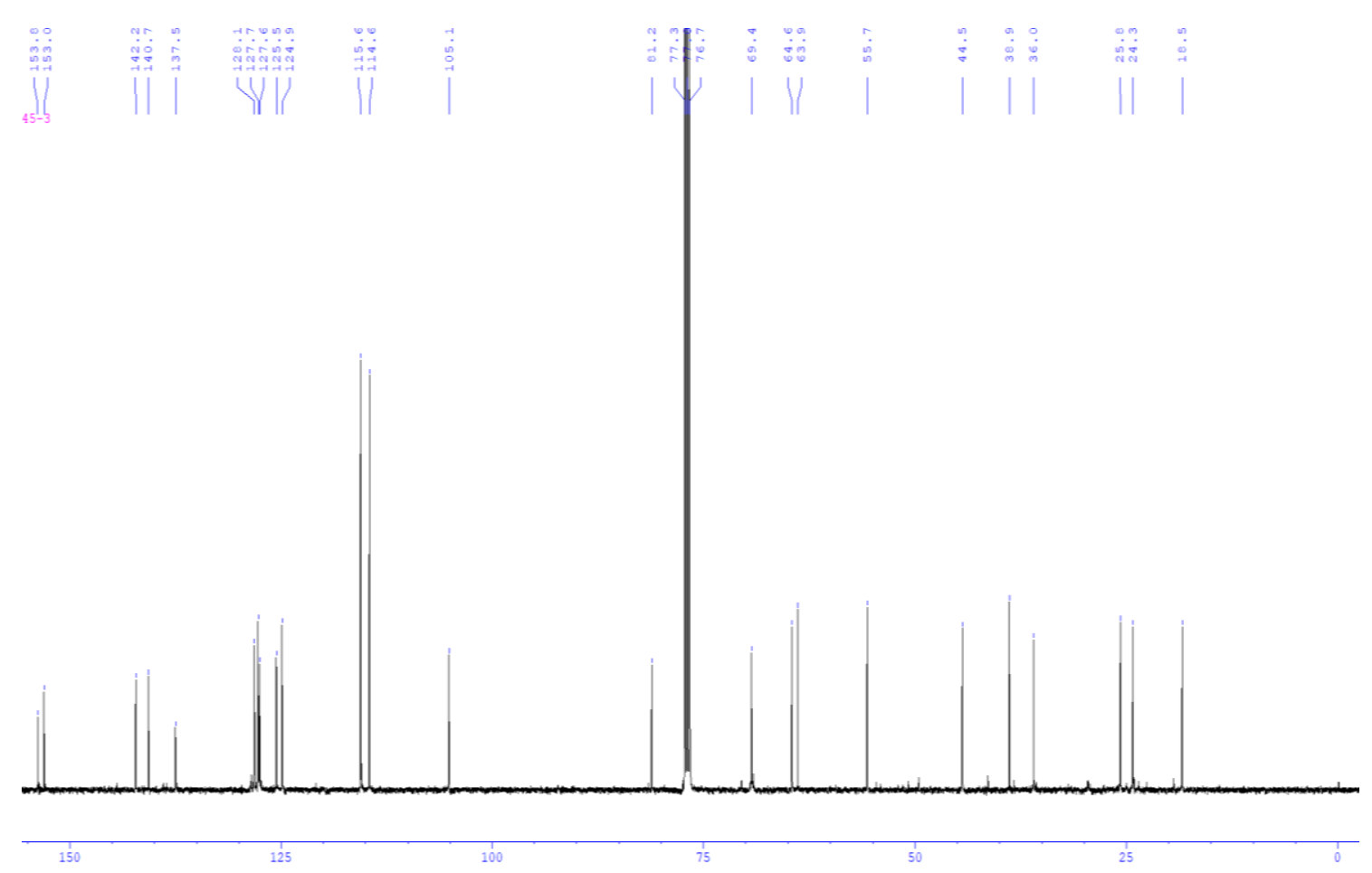


${ }^{1} \mathrm{H}$ NMR spectrum of Compound 14

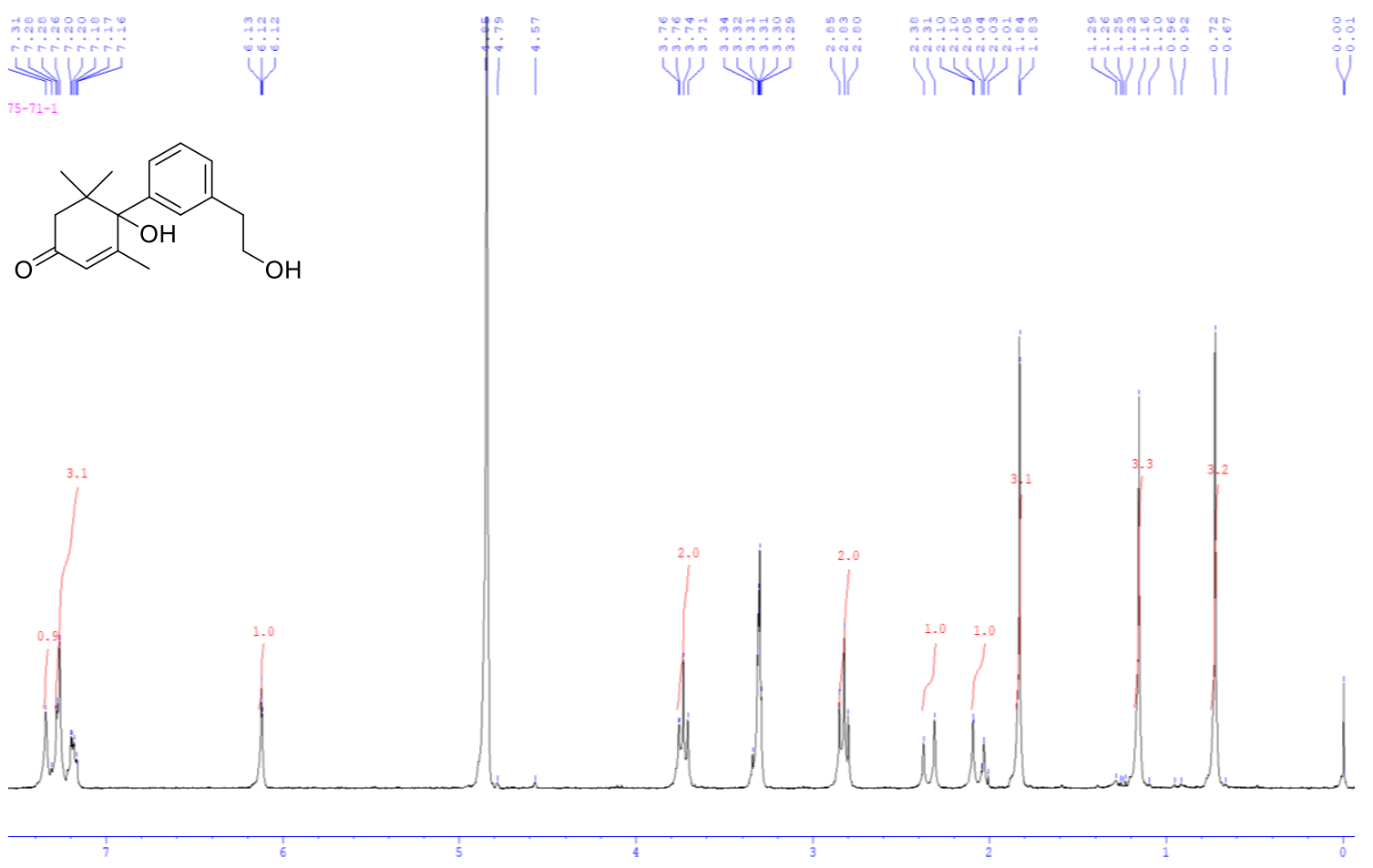

${ }^{13} \mathrm{C}$ NMR spectrum of Compound 14

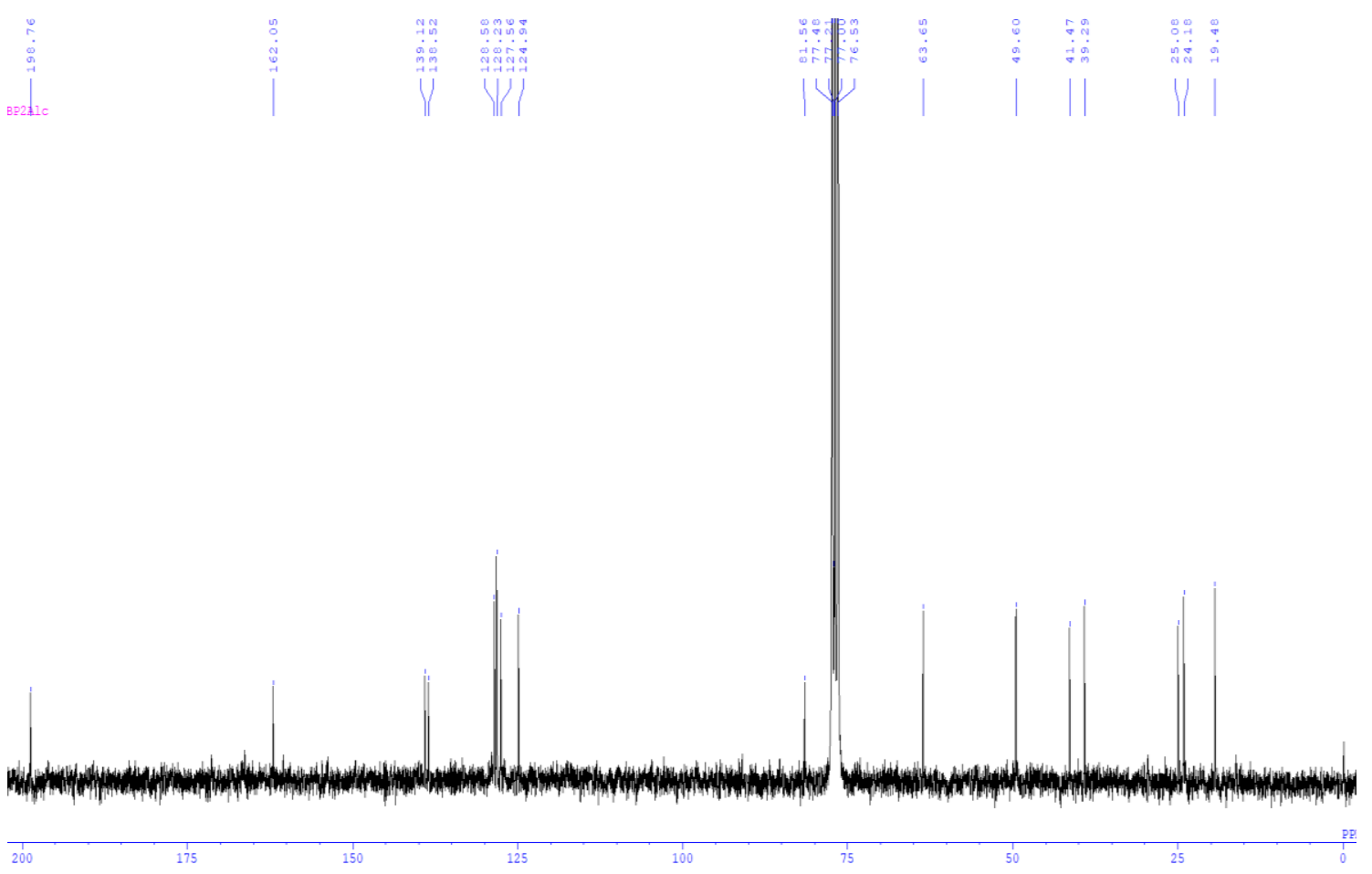


${ }^{1} \mathrm{H}$ NMR spectrum of Compound 5 (BP2A)
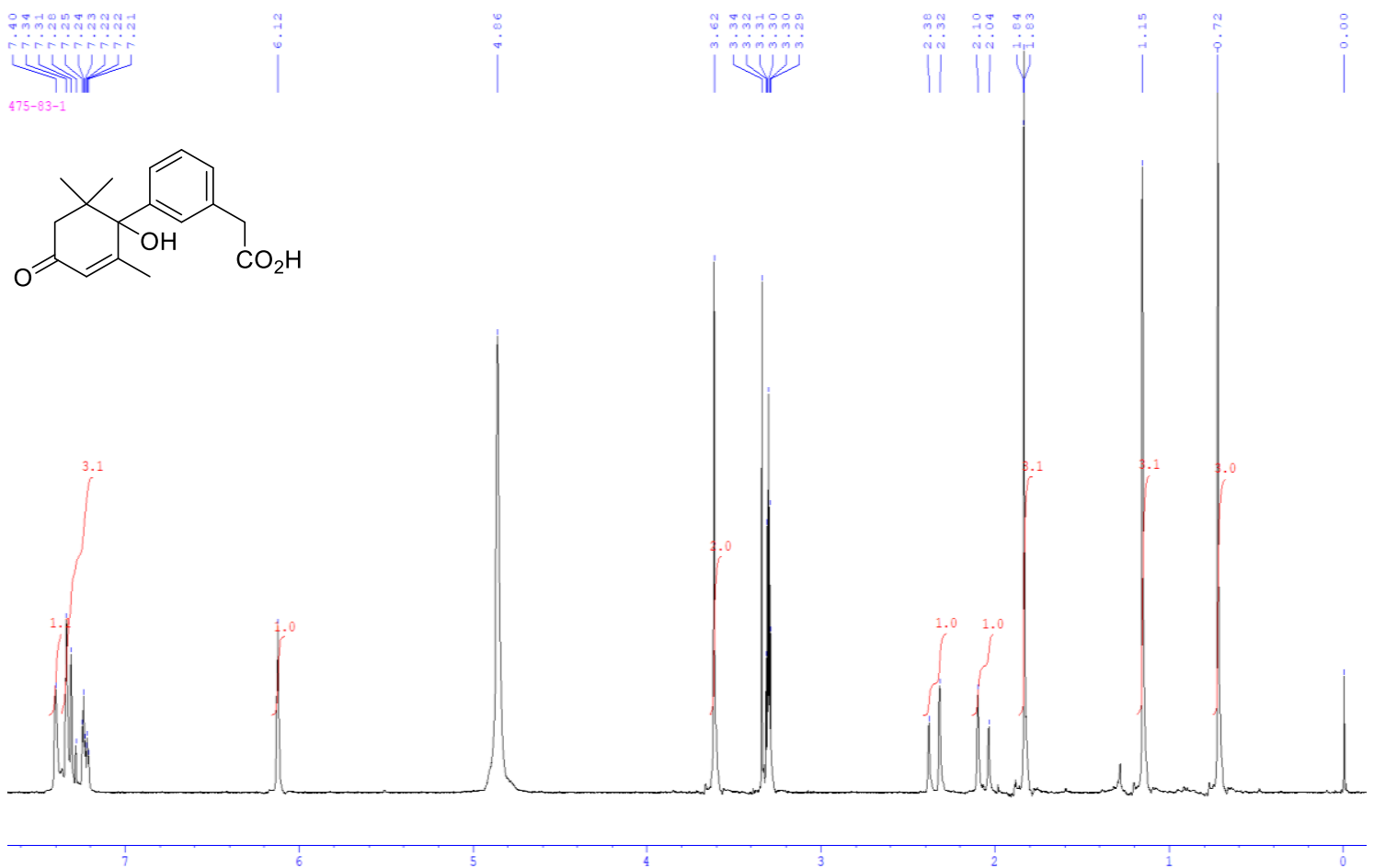

${ }^{13} \mathrm{C}$ NMR spectrum of Compound 5
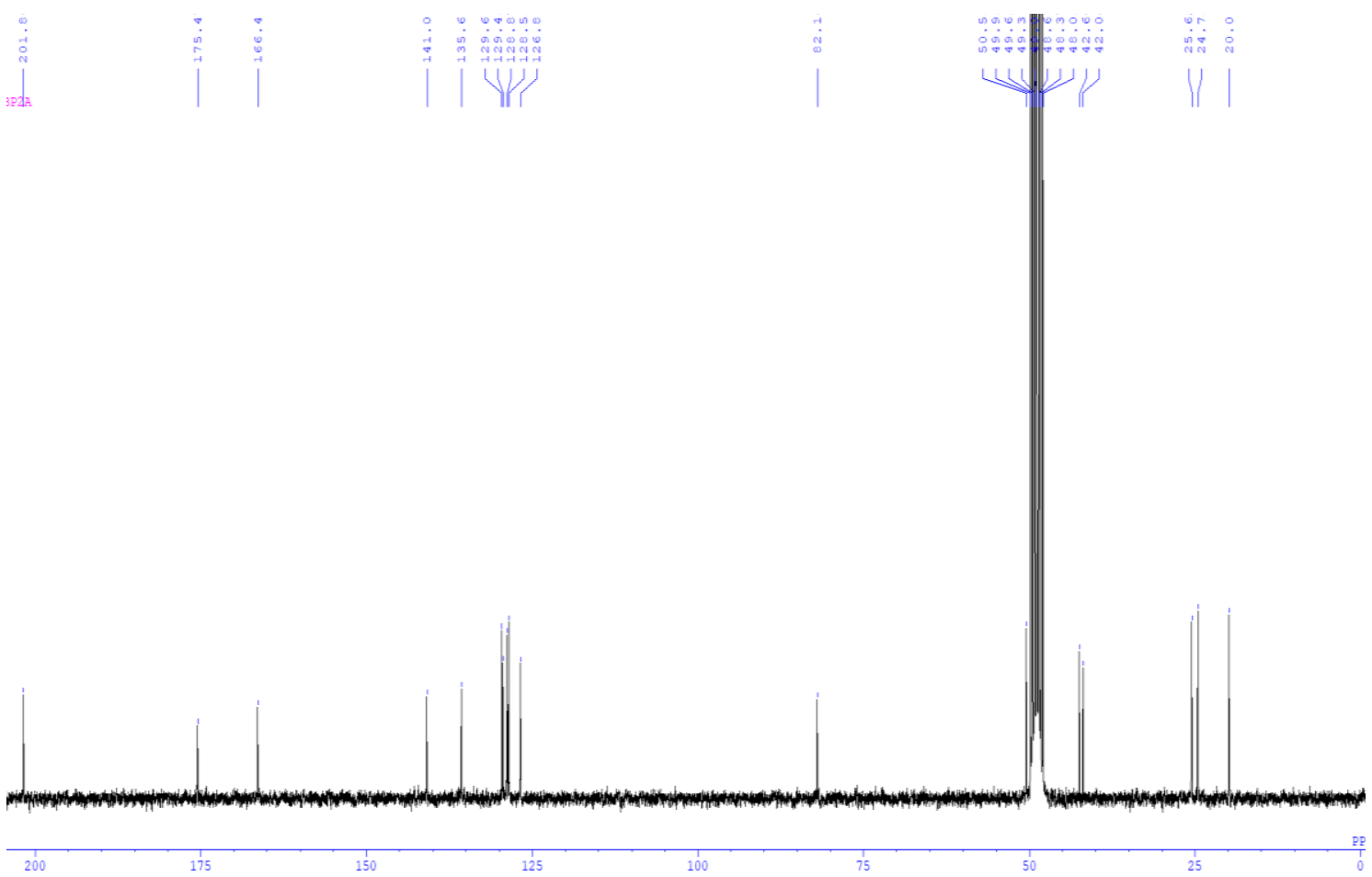
${ }^{1} \mathrm{H}$ NMR spectrum of Compound 5a

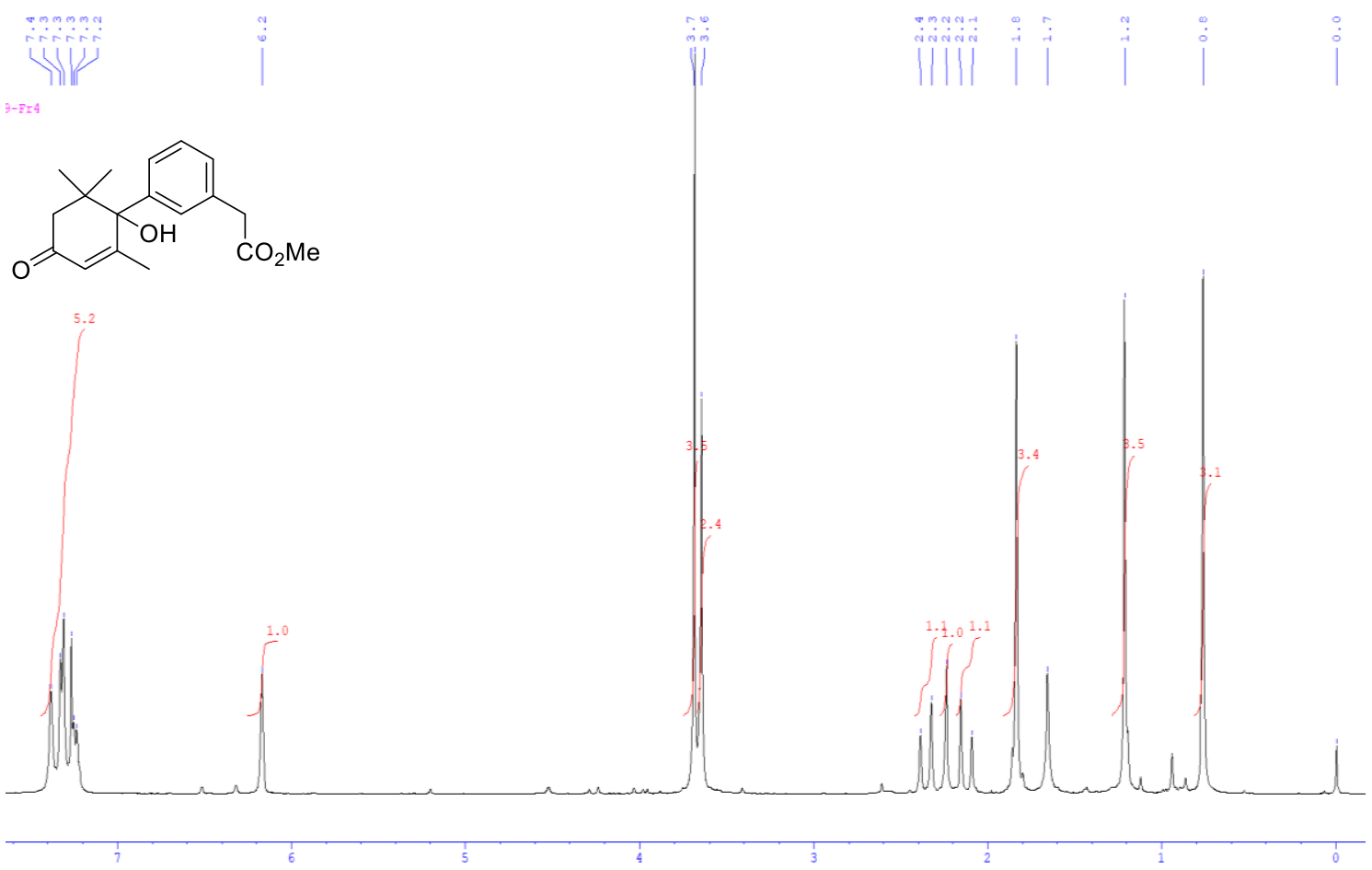

${ }^{1} \mathrm{H}$ NMR spectrum of Compound 15
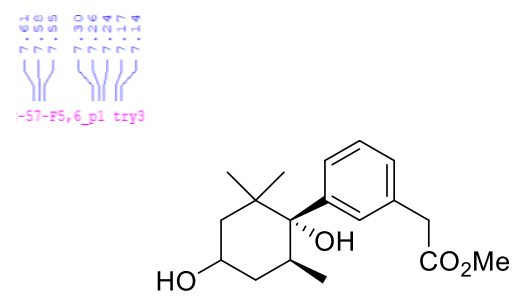

$\left(1^{\prime} R^{\star}, 2^{\prime} S^{\star}\right)$

Diastereomeric mixture at $\mathrm{C} 1{ }^{\prime}$ and $\mathrm{C} 4{ }^{\prime}$
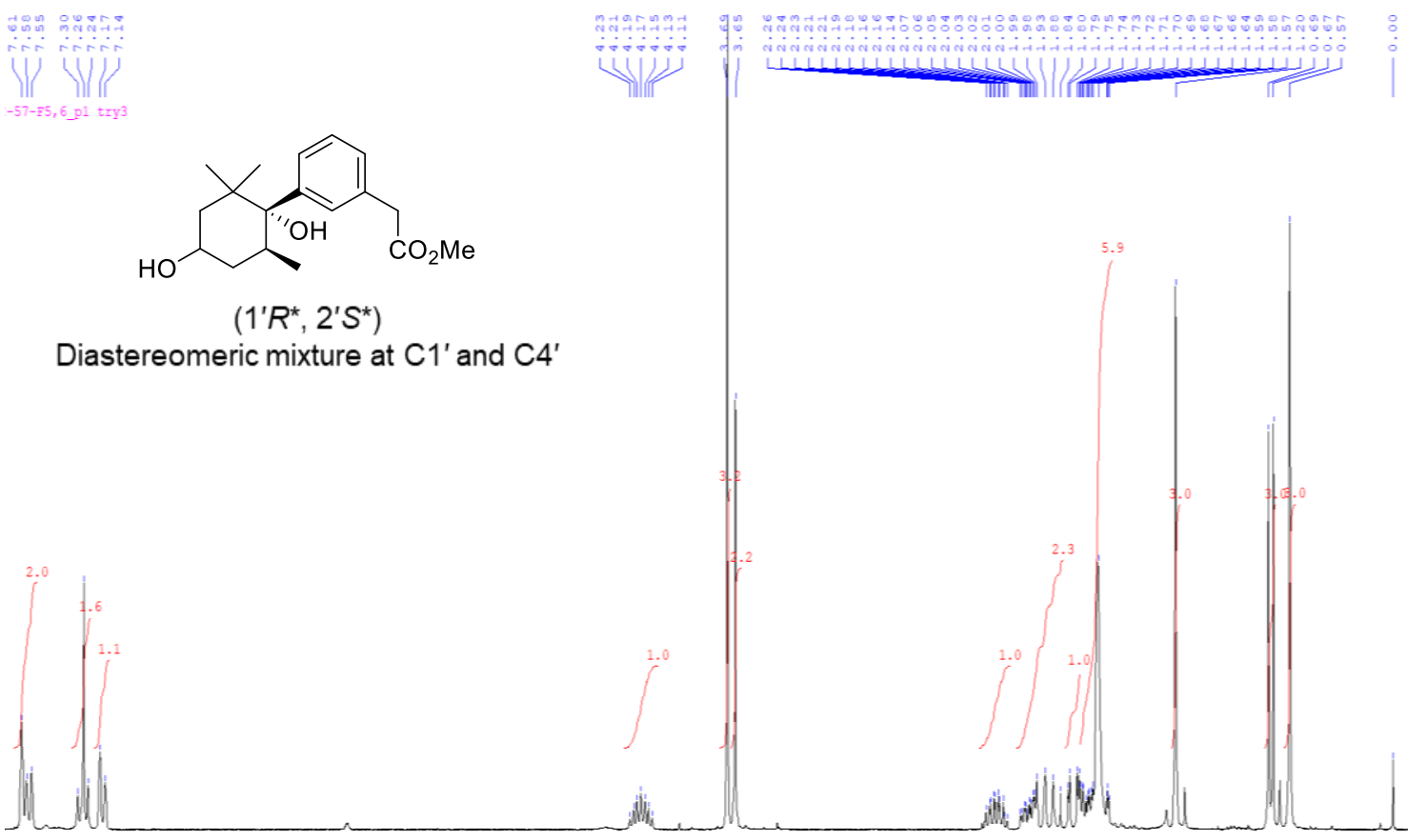
${ }^{1} \mathrm{H}$ NMR spectrum of Compound 6

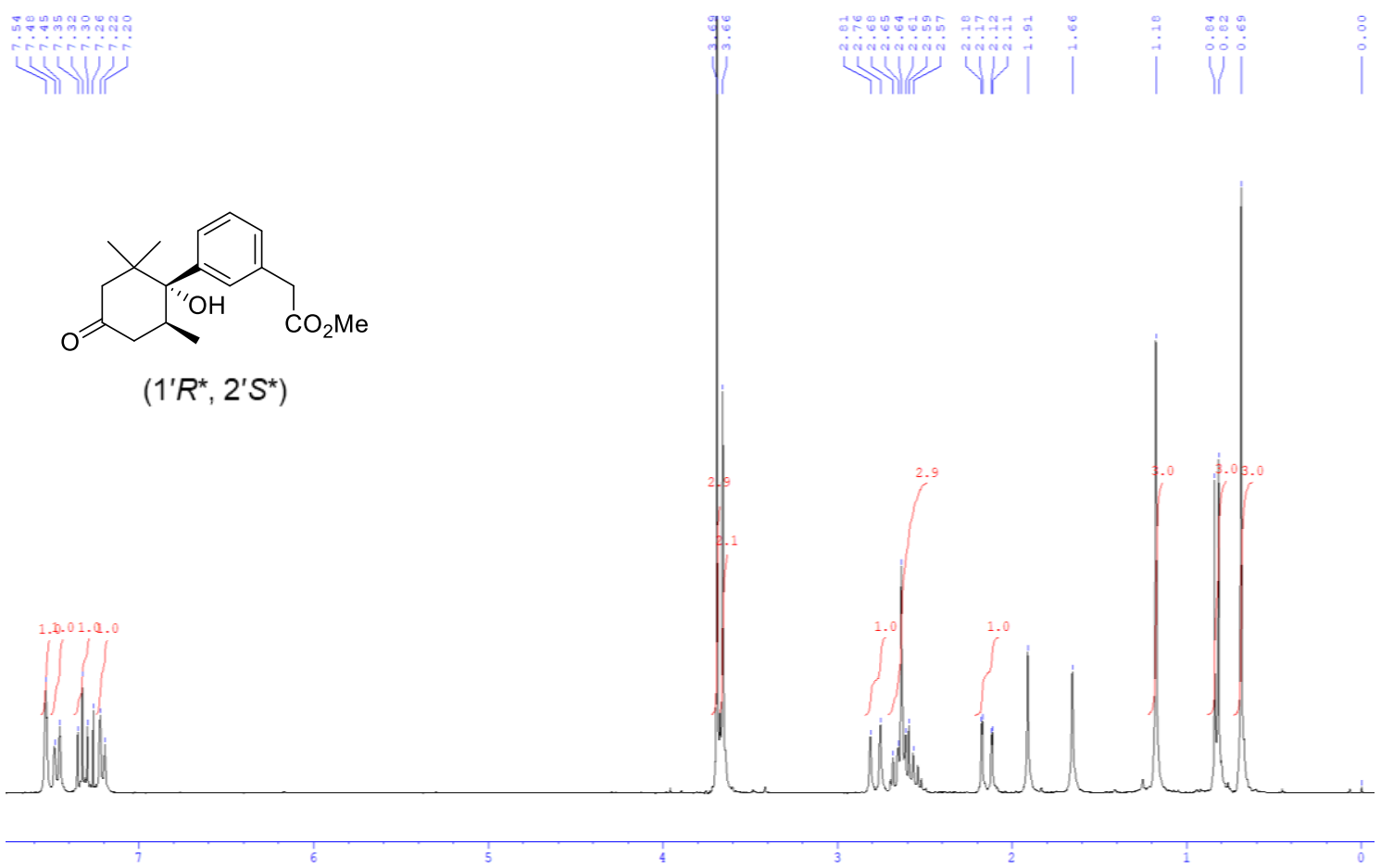

${ }^{13} \mathrm{C}$ NMR spectrum of Compound 6
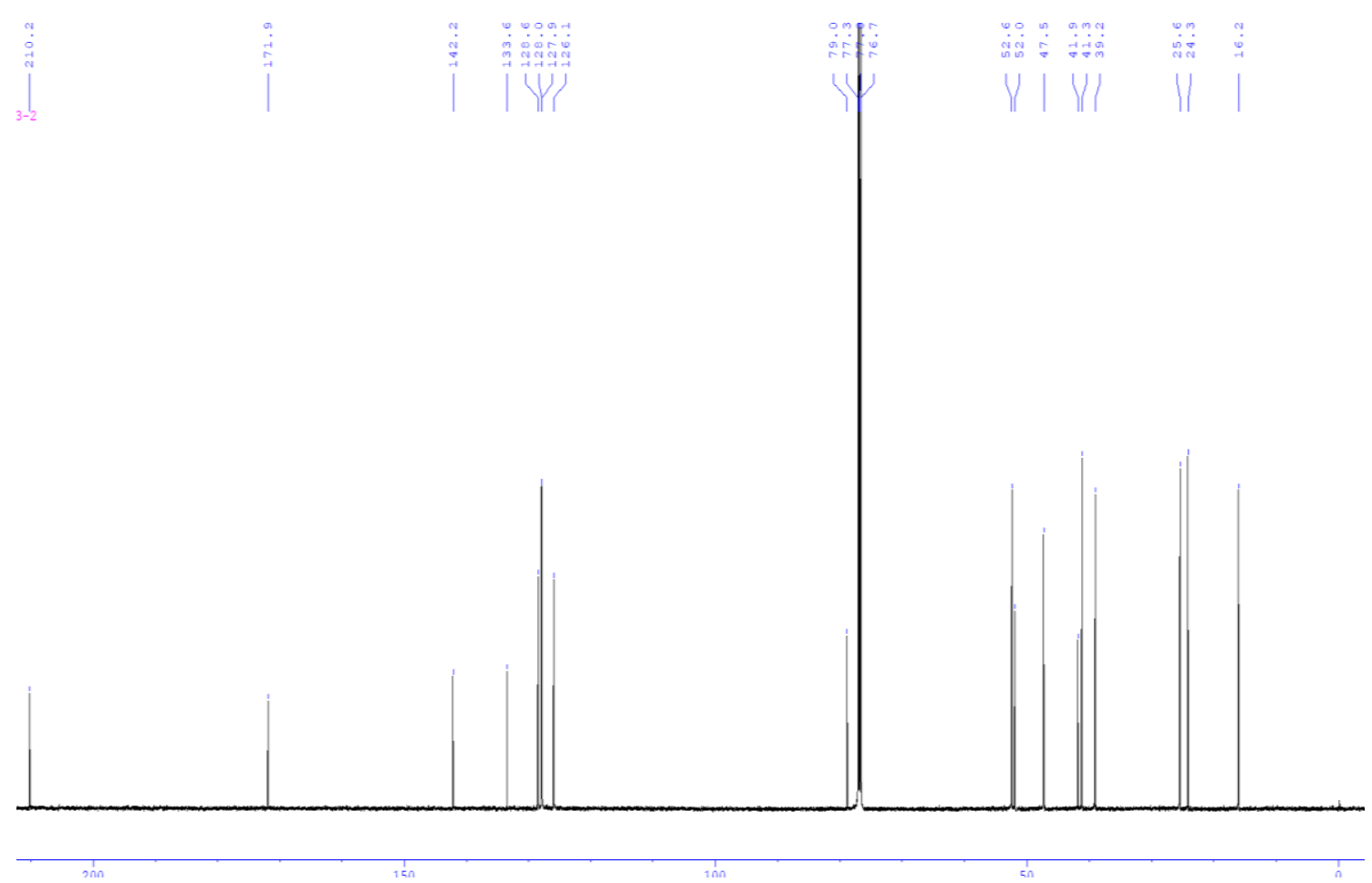
${ }^{1} \mathrm{H}$ NMR spectrum of Compound 7

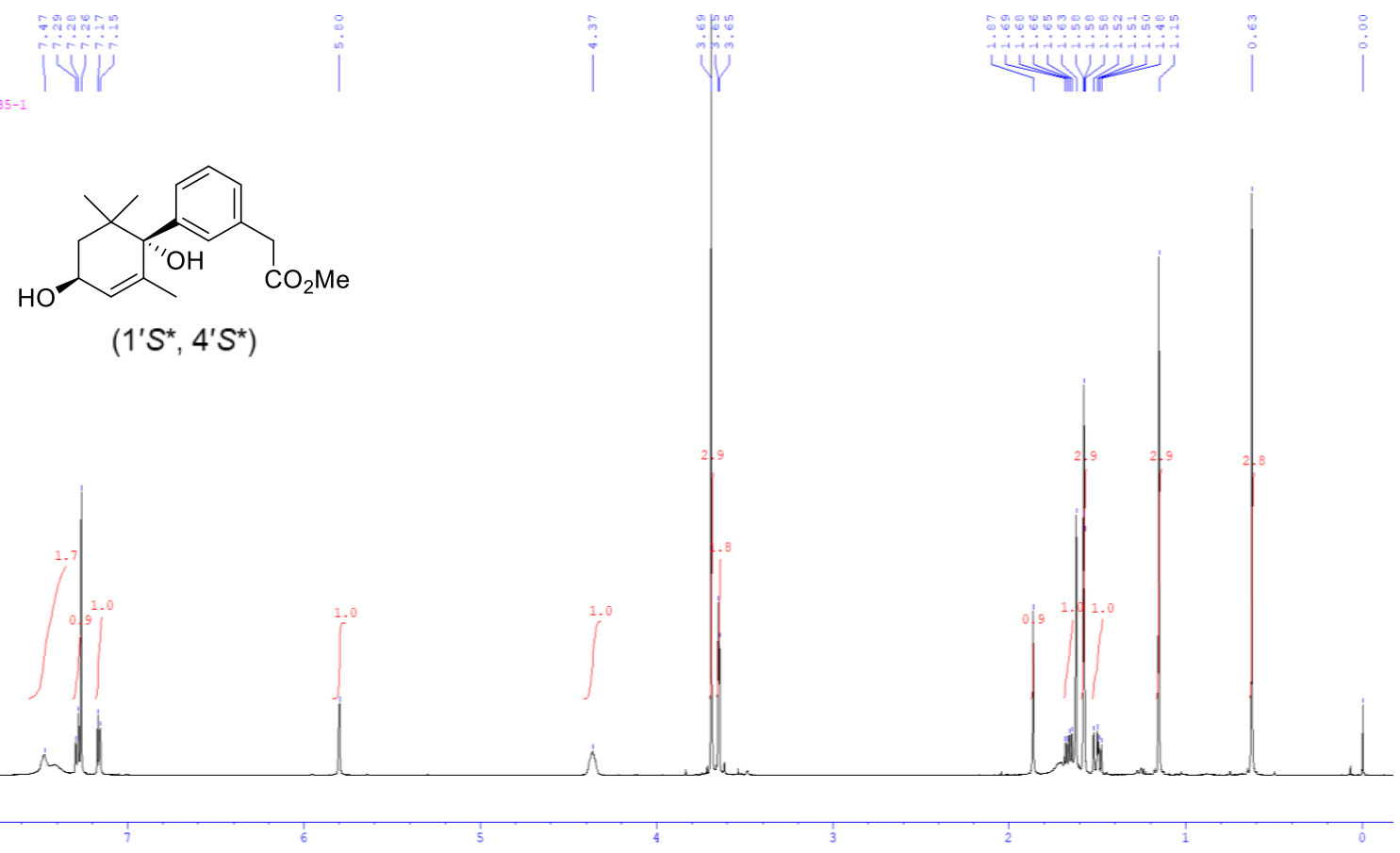

${ }^{13} \mathrm{C}$ NMR spectrum of Compound 7
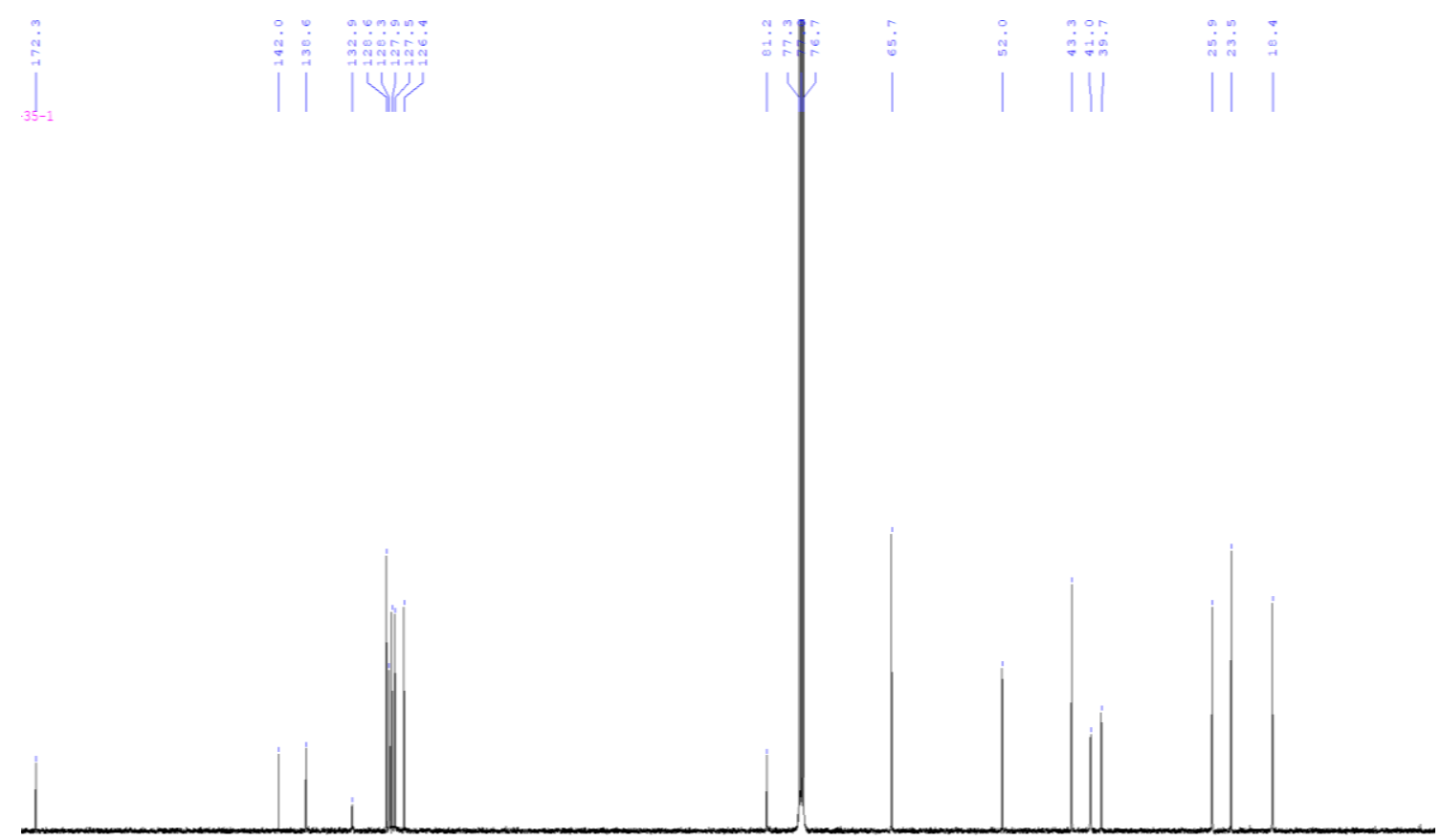

150

125

100

25 
${ }^{1} \mathrm{H}$ NMR spectrum of Compound 8
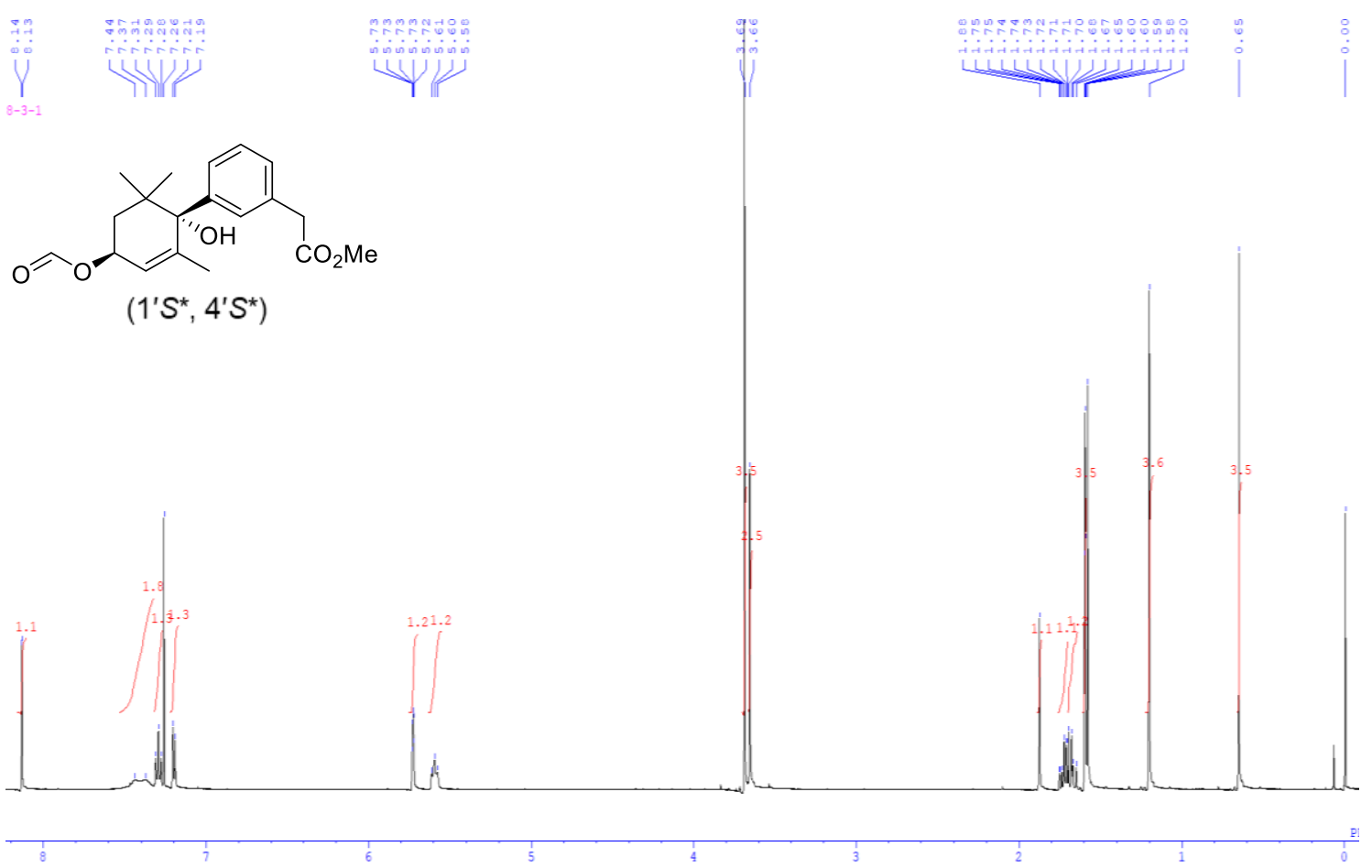

${ }^{13} \mathrm{C}$ NMR spectrum of Compound 8
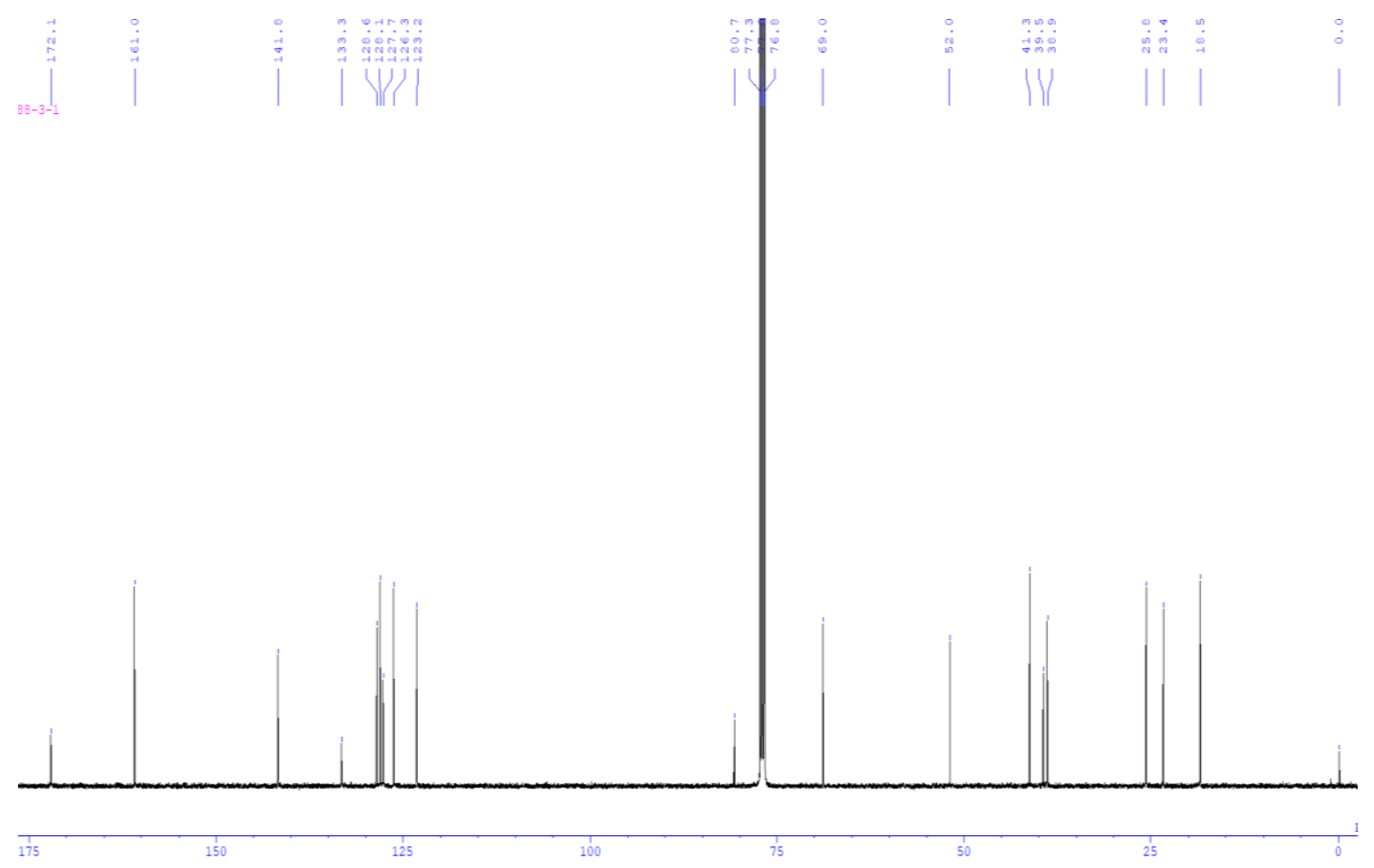
${ }^{1} \mathrm{H}$ NMR spectrum of Compound 9

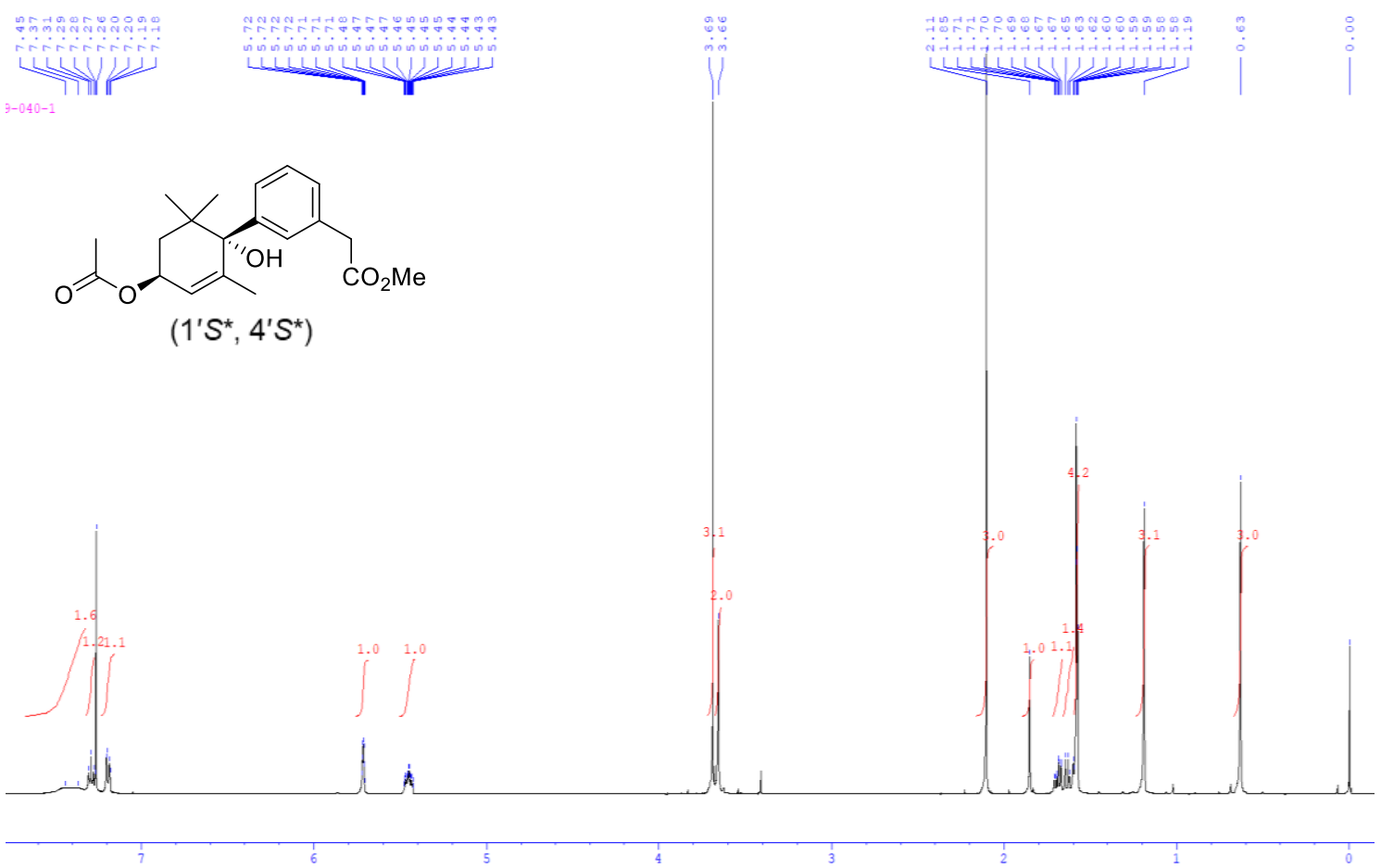

${ }^{13} \mathrm{C}$ NMR spectrum of Compound 9
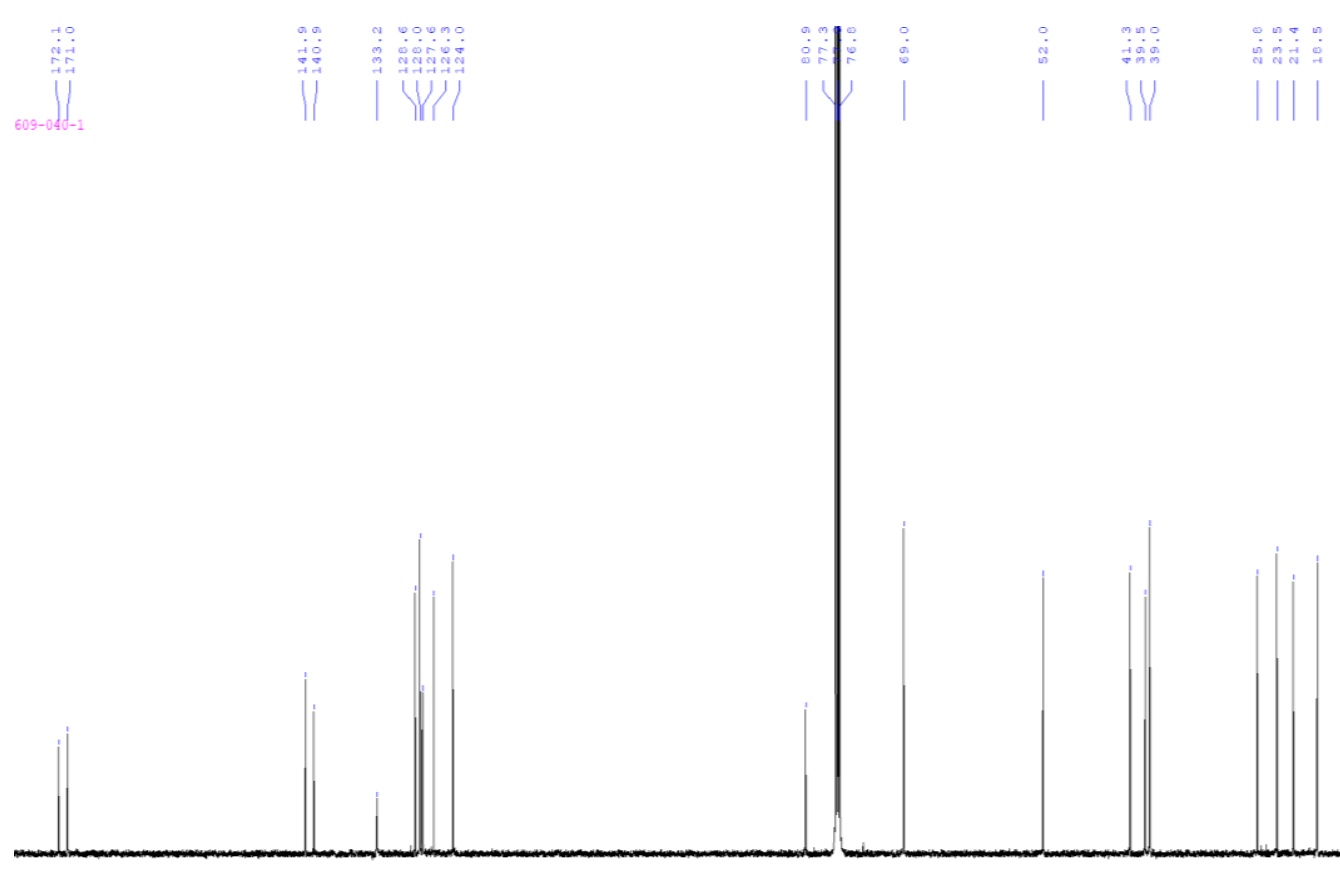

17

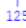

